\title{
Substrains matter in phenotyping of C57BL/6 mice
}

\author{
Kazuyuki MEKADA ${ }^{1,2)}$ and Atsushi YOSHIKI ${ }^{2)}$ \\ 1) Department of Zoology, Okayama University of Science, 1-1 Ridai-cho, Kita-ku, Okayama 700-0005, Japan \\ ${ }^{2)}$ Experimental Animal Division, RIKEN BioResource Research Center, 3-1-1 Koyadai, Tsukuba, Ibaraki 305-0074, Japan
}

\begin{abstract}
The inbred mouse strain C57BL/6 has been widely used as a background strain for spontaneous and induced mutations. Developed in the 1930s, the C57BL/6 strain diverged into two major groups in the 1950s, namely, C57BL/6J and C57BL/6N, and more than 20 substrains have been established from them worldwide. We previously reported genetic differences among C57BL/6 substrains in 2009 and 2015. Since then, dozens of reports have been published on phenotypic differences in behavioral, neurological, cardiovascular, and metabolic traits. Substrains need to be chosen according to the purpose of the study because phenotypic differences might affect the experimental results. In this paper, we review recent reports of phenotypic and genetic differences among C57BL/6 substrains, focus our attention on the proper use of C57BL/6 and other inbred strains in the era of genome editing, and provide the life science research community wider knowledge about this subject.

Key words: C57BL/6, genetic difference, phenotypic difference, single nucleotide polymorphism (SNP), substrain
\end{abstract}

\section{Origin of the C57BL/6 Mice}

The inbred mouse strain C57BL/6 has a long history. It was derived from the C57BL line, which was established in 1921 by Dr. C.C. Little, who mated littermates female 57 and male 52, which were obtained from the stock of Ms. A.E. Lathrop. This line was separated into sublines 10 and 6 in 1937, thereby establishing the C57BL/10 and C57BL/6 strains, respectively [1]. The C57BL/6 strain was introduced to the Jackson Laboratory (Bar Harbor, ME, USA) in 1948, and in 1951, the mice were sent from the Jackson Laboratory to the National Institutes of Health (NIH; Bethesda, MD, USA); thereafter, the strain was separately maintained at both institutions [2, 3]. Subsequently, the Jackson Laboratory's C57BL/6J and NIH's N strains became the major lineages of $\mathrm{C} 57 \mathrm{BL} / 6$ mice, with a large number of substrains having since been derived from each $[4,5]$. At present, seven C57BL/6 substrains are available from domestic vendors in Japan, and 11 are offered by overseas vendors (Supplementary Table 1). Various sub- strains have been maintained for many years within individual laboratories in Japan, including the National Institute of Genetics (Ms; Mishima, Japan) and the National Institute of Radiological Sciences (Nrs; Chiba, Japan), all of which are substrains of $\mathrm{C} 57 \mathrm{BL} / 6 \mathrm{~J}$ or C57BL/6N (Fig. 1). The C57BL/6J strain was the first line for which the mouse genome was sequenced [8], and it continues to be used as a representative inbred mouse strain in various life science fields. Through community effort, a highly germline-competent embryonic stem cell line was established from the C57BL/6NTac strain [9], and it has been used as a background strain in the International Knockout Mouse Project and the International Mouse Phenotyping Consortium [10-13].

We analyzed the substrain status of 2,939 genetically modified C57BL/6 mice deposited at the RIKEN BioResource Research Center (BRC) (Fig. 2). Each substrain was further subdivided into substrains supplied by several vendors. In addition, over 600 strains $(21 \%$ of the total) had a mixed genetic background of C57BL6/J and C57BL6/N or a genetic background of uncertain

(Received 29 October 2020 / Accepted 7 December 2020 / Published online in J-STAGE 14 January 2021)

Corresponding authors: K. Mekada.e-mail:mekada@zool.ous.ac.jp

A. Yoshiki.e-mail: atsushi.yoshiki@riken.jp

Supplementary Tables and Figure: refer to J-STAGE: https://www.jstage.jst.go.jp/browse/expanim

cC) $\$$ This is an open-access article distributed under the terms of the Creative Commons Attribution Non-Commercial No Derivatives CC)

(C)2021 Japanese Association for Laboratory Animal Science 


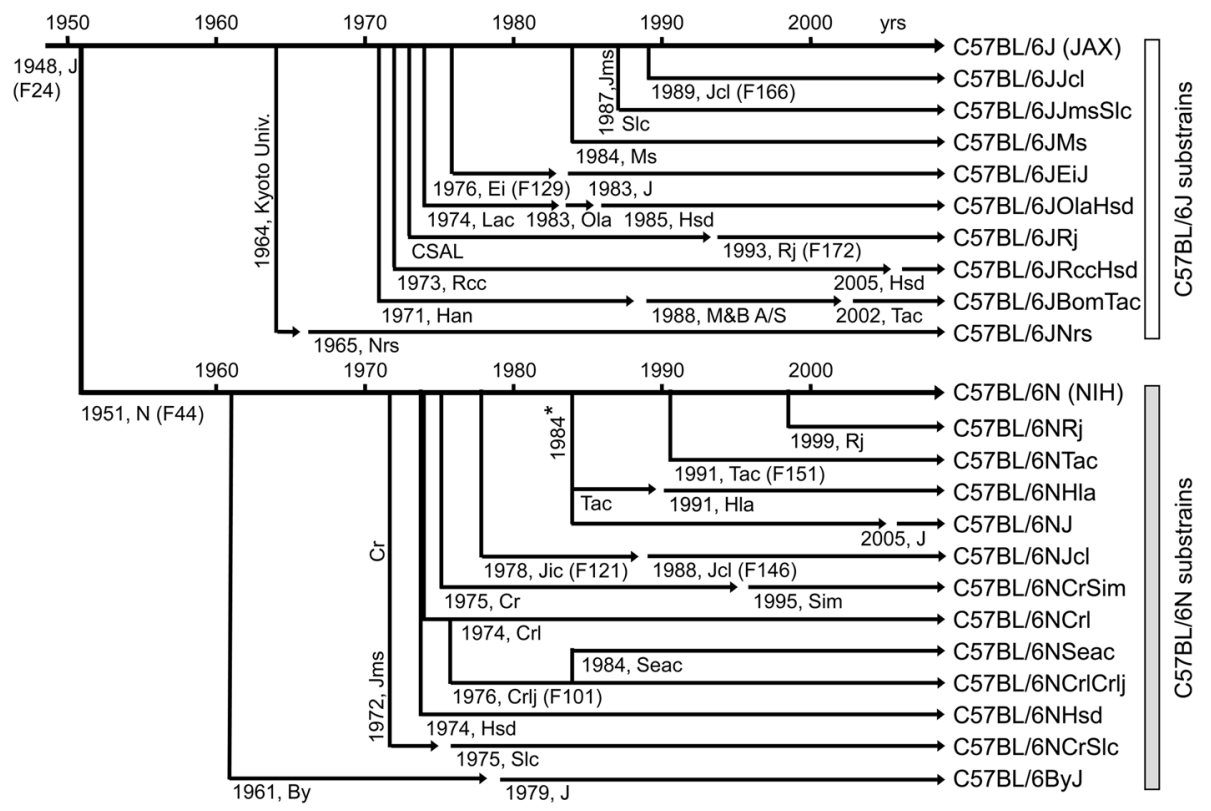

Fig. 1. Genealogy of the C57BL/6 substrains. Dates and relationships are derived from the vendors' websites and Mekada et al. (2009 and 2015) [6, 7]. Abbreviations: J, The Jackson Laboratory (JAX); Jcl, CLEA Japan, Inc.; Jms, Institute of Medical Science, Japan; Slc, Japan SLC, Inc.; Ms, National Institute of Genetics; Ei, Dr. Eva M. Eicher; Lac, Laboratory Animal Centre (MRC Carshalton Lab Animal Centre); Ola, Olac, Ltd.; Hsd, Harlan SpragueDawley, Inc.; CSAL, Centre de Sélection des Animaux de Laboratoire; Rj, Centre D’Elevage R. Janvier; Rcc, RCC Ltd.; Han, Zentralinstitut fur Versuchstierzucht, Hannover; M\&B A/S, Taconic's Bomholtgard, Denmark, facility; Tac, Taconic Biosciences, Inc.; Nrs, National Institute for Quantum and of Radiological Science and Technology; N, National Institutes of Health; Hla, Hilltop Lab Animals, Inc.; Jic, Central Institute for Experimental Animals, Japan; Cr, NCI, DCTD Animal Production Program; Sim, Simonsen Laboratories, Inc.; Crl, Charles River Laboratories; Crlj, Charles River Laboratories Japan; Seac, Seac Yoshitomi, Ltd. (Kyodo Co., Ltd.); By, Dr. Donald W. Bailey. *Derived from embryos frozen in 1984.

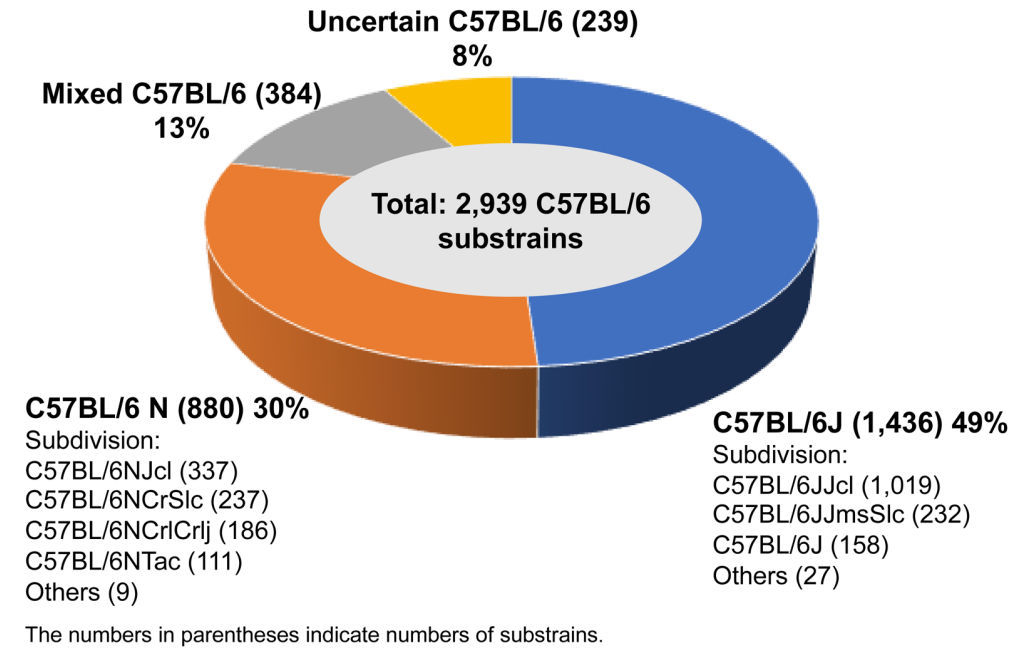

Fig. 2. Summary of a survey on the use of C57BL/6 substrains in Japan. According to information provided by the developer scientists of the 2,939 mouse strains deposited at RIKEN BRC, 49\% were crossed with C57BL/6J substrains, including $\mathrm{C} 57 \mathrm{BL} / 6 \mathrm{JJcl}, \mathrm{C} 57 \mathrm{BL} / 6 \mathrm{JJmsSlc}$, and $\mathrm{C} 57 \mathrm{BL} / 6 \mathrm{~J}$, and $30 \%$ were crossed with C57BL/6N substrains, including C57BL/6NJcl, C57BL/6NCrSlc, $\mathrm{C} 57 \mathrm{BL} / 6 \mathrm{NCrlCrlj}$ (including $\mathrm{C} 57 \mathrm{BL} / 6 \mathrm{NCrl}$ in 35 strains), and $\mathrm{C} 57 \mathrm{BL} / 6 \mathrm{NTac}$. Another $13 \%$ were crossed with C57BL/6 substrains of mixed background, and $8 \%$ were crossed with uncertain $\mathrm{C} 57 \mathrm{BL} / 6$ substrains. 
C57BL/6 substrain. We interviewed several scientists who either developed or deposited these strains and found that they had purchased and used the mice without knowing about the substrain distinctions or had not kept detailed breeding records. Similar occurrences have been reported elsewhere. Over $70 \%$ of the genetically engineered strains generated at German and Austrian institutions had a mixed genetic background [14]. A survey of Finnish institutions revealed that $39.5 \%$ of researchers did not consider the importance of differences among substrains and that $26 \%$ did not know which C57BL/6 substrain they had used [15]. Furthermore, $58 \%$ of the studies that were published in Diabetes during 20102014 and involved genetically modified mice provided incomplete descriptions of the background strains [16]. Despite the reported non-negligible phenotypic differences among C57BL/6 substrains, there seems to be little awareness of the importance of substrain selection within the research community.

\section{Phenotypic Differences Among C57BL/6 Substrains Caused by Identified Genetic Variants}

To date, dozens of papers have reported various phenotypic differences among C57BL/6 substrains (Table 1). This information is classified according to the phenotype terms defined in the Mammalian Phenotype Ontology [116] and includes descriptions of phenotypes or phenotyping tests, the names of tested C57BL/6 substrains, and relevant references. Moreover, several of these phenotypic differences have been analyzed with the aim of identifying causative genes or genomic regions, as described below (summarized in Table 2).

The C57BL/6J strain is missing the exon that encodes the nicotinamide nucleotide transhydrogenase (Nnt) gene, which plays an important role in glucose homeostasis and insulin secretion, and therefore has abnormal glucose tolerance and impaired insulin secretion [117, $118,126]$. A study using mitogen-activated protein kinase 9 (Mapk9) knockout mice demonstrated that susceptibility to acetaminophen-induced liver injury was influenced by the presence or absence of the Nnt gene defect carried by C57BL/6 mice [127]. The Nnt gene mutation in the $\mathrm{C} 57 \mathrm{BL} / 6 \mathrm{~J}$ strain is a prominent phenotype-associated mutation in $\mathrm{C} 57 \mathrm{BL} / 6$ substrains that affects protein expression in the mitochondria of many tissues and consequently many different metabolic traits $[62,72,78,82,88,106,128]$. The $N n t$ gene deletion status differs among $\mathrm{C} 57 \mathrm{BL} / 6 \mathrm{~J}$ substrains, and the $N n t$ gene defect likely originated in $\mathrm{C} 57 \mathrm{BL} / 6 \mathrm{~J}$ mice at the Jackson Laboratory after 1976 (Fig. 3).
C57BL/6JOlaHsd mice are known to lack a $365 \mathrm{~kb}$ genomic region that includes the synuclein, alpha (Snca) and the nearby multimerin 1 (Mmrnl) gene $[119,120]$. SNCA aggregates in the nervous system of individuals with Parkinson's disease [129]. Loss of the Snca gene in C57BL/6JOlaHsd mice does not appear to contribute to prion disease-mediated synaptotoxicity or neurodegeneration but may affect motor neuron degeneration [130-133]. In addition, the C57BL/6JOlaHsd strain has a low trabecular bone mass, which has been shown to be associated with the lack of Snca and Mmrnl genes, suggesting a role for these genes in bone metabolism [110]. Deletion of this genomic region is specific to the C57BL/6JOlaHsd strain; the mutation has not been identified in C57BL/6JRccHsd, C57BL/6J, C57BL/6NCrl, and C57BL/6NHsd strains [119]. Notably, we confirmed that the genotype is normal in other C57BL/6J and C57BL/6N substrains available in Japan (Supplementary Fig. 1). Furthermore, partial deletion of a chromosomal region was recently observed in C57BL/6JBomTac mice. In this strain, approximately $40 \mathrm{Mb}$ of the long arm of the $\mathrm{Y}$ chromosome is deleted, and an increased rate of sperm morphological abnormalities, unbalanced sex ratio, and deregulation of several transcripts expressed in the testes have also been observed [70, 125].

Similarly, genetic mutations affecting physiological functions have been reported in $\mathrm{C} 57 \mathrm{BL} / 6 \mathrm{~N}$ substrains. A nonsense mutation (retinal degeneration $8, r d 8$ ) that converts the amino acid codon of the crumbs family member 1, photoreceptor morphogenesis associated (Crbl) gene into a termination codon occurs in C57BL/6N substrains [121, 122]. Affected mice present with the typical lesions of $r d 8$, which are detected by fundoscopy and histopathology at as early as 6 weeks of age. Although this mutation is seen in $\mathrm{C} 57 \mathrm{BL} / 6 \mathrm{~N}$ substrains, C57BL/6J substrains have the wild-type genotype [121].

C57BL/6NHsd mice have a copy-number variant in the dedicator of cytokinesis 2 (Dock2) gene, which has been shown to affect $\mathrm{B}$ cell signaling and immune tolerance, but this is not found in other C57BL/6 substrains $[123,134]$. The dysfunction of this gene has likely contributed to the negative outcomes of experiments using the sialic acid acetylesterase (Siae) knockout mice with an unclear C57BL/6 origin. Although the Siae gene was initially thought to be involved in B cell development and signal transduction, it was found that congenic mice generated by backcrossing to the C57BL6J strain did not reproduce the same negative outcomes. After much research, the cause was identified as a mutation in the Dock2 gene of the C57BL/6NHsd strain [134]. 
Table 1. C57BL/6 substrains used for testing various phenotypes

\begin{tabular}{|c|c|c|c|}
\hline Phenotype terms & Descriptions and/or tests & C57BL/6 substrains tested & Publication \\
\hline \multirow[t]{41}{*}{$\begin{array}{l}\text { Behavior/neurological } \\
\text { phenotype }\end{array}$} & Aggression, light-dark box, nest-building & $\begin{array}{l}\text { C57BL/6JNmg (Nijmegen Univ.), C57BL/6JKun } \\
\text { (Nijmegen Univ.) }\end{array}$ & {$[17]$} \\
\hline & Alcohol preference & $\begin{array}{l}\text { C57BL/6J (JAX), C57BL/6NCrSim (Simonsen } \\
\text { Lab) }\end{array}$ & [18] \\
\hline & & C57BL/6J (JAX), C57BL/6NCrl (CRL) & [19] \\
\hline & & C57BL/6J (JAX), C57BL/6J (Univ. of Albeta) & {$[20]$} \\
\hline & & C57BL/6J (JAX), C57BL/6NCrl (CRL) & [21] \\
\hline & Alcohol preference and innate immune response & C57BL/6J (JAX), C57BL/6NJ (JAX) & {$[22]$} \\
\hline & Behavioral response to amphetamine & C57BL/6J (JAX), C57BL/6By (JAX) & [23] \\
\hline & Conditioned place preference & C57BL/6J (JAX), C57BL/6NCrl (CRL) & {$[24]$} \\
\hline & Corticosterone sensitivity & C57BL/6J (JAX), C57BL/6NCrl (CRL) & {$[25]$} \\
\hline & Degree of cuprizone-induced binge-like eating reduction & C57BL/6J (JAX), C57BL/6NJ (JAX) & [26] \\
\hline & Degree of naloxone-induced conditioned place aversion & C57BL/6J (JAX), C57BL/6NJ (JAX) & [27] \\
\hline & $\begin{array}{l}\text { Eight-arm radial maze, elevated plus maze, open field, } \\
\text { rotarod, Porsolt forced swim, prepulse inhibition, wire } \\
\text { hang }\end{array}$ & $\begin{array}{l}\text { C57BL/6J (JAX), C57BL/6NCrlCrlj (CRL Japan), } \\
\text { C57BL/6NCrSlc (Japan SLC) }\end{array}$ & [28] \\
\hline & $\begin{array}{l}\text { Elevated plus maze, fear conditioning, light-dark box, } \\
\text { prepulse inhibition, open field, social approach, acoustic } \\
\text { startle }\end{array}$ & $\begin{array}{l}\text { C57BL/6J (JAX), C57BL/6JRccHsd (Envigo), } \\
\text { C57BL/6JRj (Janvier Labs), C57BL/6NCrl } \\
\text { (CRL), C57BL/6NHsd (Envigo), C57BL/6NRj } \\
\text { (Janvier Labs) }\end{array}$ & [15] \\
\hline & Elevated plus maze, hole board, light-dark box & C57BL/6JOlaHsd (Envigo), C57BL/6NCrl (CRL) & [29] \\
\hline & Fear conditioning & C57BL/6JIco (CRL), C57BL/6NCrl (CRL) & {$[30]$} \\
\hline & & C57BL/6J (Hsd) (Envigo), C57BL/6NCrl (CRL) & [31] \\
\hline & & $\begin{array}{l}\text { C57BL/6J (JAX), C57BL/6JOlaHsd (Envigo), } \\
\text { C57BL/6NCrl (CRL) }\end{array}$ & {$[32]$} \\
\hline & & C57BL/6JOlaHsd (Envigo), C57BL/6NCrl (CRL) & [33] \\
\hline & & $\begin{array}{l}\text { C57BL/6JOlaHsd (Envigo), C57BL/6NCrlBR } \\
\text { (CRL) }\end{array}$ & {$[34]$} \\
\hline & Fear conditioning, hot plate, rotarod, tail withdrawal & $\begin{array}{l}\text { C57BL/6J (JAX), C57BL/6NCrl (CRL), } \\
\text { C57BL/6NHsd (Envigo), C57BL/6NTac (TAC) }\end{array}$ & [35] \\
\hline & Fear conditioning, Morris water maze, open field, rotarod & C57BL/6J (JAX), C57BL/6NJ (JAX) & [36] \\
\hline & Food consumption in conditioned site preference & C57BL/6J (JAX), C57BL/6NJ (JAX) & {$[37]$} \\
\hline & High-fat diet-induced mechanical sensitivity & $\begin{array}{l}\text { C57BL/6J (JAX), C57BL/6NCrl (CRL), } \\
\text { C57BL/6NJ (JAX) }\end{array}$ & {$[38]$} \\
\hline & Light-dark box & C57BL/6J (Envigo), C57BL/6ChR (CRL) & [39] \\
\hline & $\begin{array}{l}\text { Locomotor activity and anxiety-like behavior during the } \\
\text { postpartum period }\end{array}$ & C57BL/6J (JAX), C57BL/6JJcl (CLEA Japan) & {$[40]$} \\
\hline & Locomotor response to cocaine & C57BL/6J (JAX), C57BL/6N (NCI) & [41] \\
\hline & $\begin{array}{l}\text { Metabolic and behavioral response to shortened 21-h day } \\
\text { and high-fat diet }\end{array}$ & C57BL/6J (JAX), C57BL/6NCrl (CRL) & [42] \\
\hline & Morris water maze & C57BL/6J (JAX), C57BL/6NTac (TAC) & [43] \\
\hline & Open field & C57BL/6J (JAX), C57BL/6NTac (TAC) & [44] \\
\hline & Open field, rotarod & $\begin{array}{l}\text { C57BL/6JBomTac (TAC), C57BL/6NCrljOri (Ori- } \\
\text { ent Bio), C57BL/6NTacSam (Samtako Bio) }\end{array}$ & [45] \\
\hline & Prepulse inhibition & C57BL/6J (JAX), C57BL/6NHsd (Envigo) & [46] \\
\hline & Response to formalin-induced pain & C57BL/6J (JAX), C57BL/6NCrl (CRL) & [47] \\
\hline & $\begin{array}{l}\text { Response to circadian disruption and wheel-running } \\
\text { access }\end{array}$ & C57BL/6J (JAX), C57BL/6NCrl (CRL) & [48] \\
\hline & Response to neuropathic pain & C57BL/6NCrl (CRL), C57BL/6NTac (TAC) & [49] \\
\hline & Sensitivity to the convulsant pilocarpine & C57BL/6J (JAX), C57BL/6NJ (JAX) & {$[50]$} \\
\hline & & $\begin{array}{l}\text { C57BL/6J (JAX), C57BL/6JOlaHsd (Envigo), } \\
\text { C57BL/6NCrl (CRL), C57BL/6NHsd (Envigo) }\end{array}$ & [51] \\
\hline & Sensitivity to nicotine & C57BL/6J (JAX), C57BL/6NCrl (CRL) & [52] \\
\hline & Sensitivity to thermal nociception & C57BL/6J (JAX), C57BL/6NJ (JAX) & [53] \\
\hline & Susceptibility to cocaine-induced seizure & C57BL/6J (JAX), C57BL/6ByJ (JAX) & {$[54]$} \\
\hline & Susceptibility to pilocarpine-induced status epilepticus & $\begin{array}{l}\text { C57BL/6JJcl (CLEA Japan), C57BL/6NJcl (CLEA } \\
\text { Japan) }\end{array}$ & {$[55]$} \\
\hline & Tail suspension & C57BL/6J (JAX), C57BL/6NHsd (Envigo) & [56] \\
\hline
\end{tabular}


Table 1. (Continued)

\begin{tabular}{|c|c|c|c|}
\hline Phenotype terms & Descriptions and/or tests & C57BL/6 substrains tested & Publication \\
\hline \multirow[t]{13}{*}{$\begin{array}{l}\text { Cardiovascular system } \\
\text { phenotype }\end{array}$} & $\begin{array}{l}\text { Cardiac effects of tribromoethanol and ketamine-mid- } \\
\text { azolam }\end{array}$ & C57BL/6J (JAX), C57BL/6NCrl (CRL) & {$[57]$} \\
\hline & Cardiac functional and metabolic flux parameters & C57BL/6J (JAX), C57BL/6NCrl (CRL) & {$[58]$} \\
\hline & Echocardiographic and electrocardiographic values & C57BL/6J (HZM), C57BL/6N (HZM) & {$[59]$} \\
\hline & Incidence of cardiac rupture after myocardial infarction & C57BL/6J (JAX), C57BL/6J (Hsd) (Envigo) & {$[60]$} \\
\hline & Incidence of dilated cardiomyopathy & C57BL/6J (JAX), C57BL/6NTac (TAC) & {$[61]$} \\
\hline & High-fat diet-induced vascular superoxide & C57BL/6J (JAX), C57BL/6NJ (JAX) & {$[62]$} \\
\hline & Response to Ang II-dependent left ventricle remodeling & C57BL/6J (JAX), C57BL/6NJ (JAX) & {$[63]$} \\
\hline & Response to left ventricular pressure overload & $\begin{array}{l}\text { C57BL/6J (JAX), C57BL/6NCrl (CRL), } \\
\text { C57BL/6NTac (TAC) }\end{array}$ & {$[64]$} \\
\hline & Response to neonatal hypoxia/ischemia & C57BL/6J (JAX), C57BL/6NCrl (CRL) & {$[65]$} \\
\hline & Response to transverse aortic constriction stimulation & C57BL/6J (JAX), C57BL/6NTac (TAC) & {$[66]$} \\
\hline & Salt sensitivity of blood pressure & C57BL/6J (JAX), C57BL/6NTac (TAC) & {$[67]$} \\
\hline & Systolic blood pressure level & C57BL/6J (JAX), C57BL/6NJ (JAX) & {$[68]$} \\
\hline & Vulnerability to neonatal hypoxia-ischemia & $\begin{array}{l}\text { C57BL/6J (Saarland Univ.), C57BL/6N (Saarland } \\
\text { Univ.) }\end{array}$ & {$[69]$} \\
\hline \multirow[t]{3}{*}{ Cellular phenotype } & Abnormal sperm head morphology & C57BL/6JBomTac (TAC), C57BL/6NTac (TAC) & {$[70]$} \\
\hline & $\begin{array}{l}\text { Hydrogen peroxide-producing capacities of liver mito- } \\
\text { chondria }\end{array}$ & C57BL/6J (JAX), C57BL/6NCrl (CRL) & [71] \\
\hline & Mitochondrial redox abnormalities & C57BL/6J (JAX), C57BL/6JUnib (CEMIB) & {$[72]$} \\
\hline \multirow[t]{3}{*}{ Embryonic phenotype } & Incidence of fetal alcohol syndrome & C57BL/6J (JAX), C57BL/6NCrl (CRL) & {$[73]$} \\
\hline & Patterns of alcohol-induced facial dysmorphology & C57BL/6J (JAX), C57BL/6NHsd (Envigo) & {$[74]$} \\
\hline & Susceptibility to Porphyromonas gingivalis & C57BL/6J (JAX), C57BL/6NJ (JAX) & {$[75]$} \\
\hline $\begin{array}{l}\text { Endocrine/exocrine } \\
\text { gland phenotype }\end{array}$ & Susceptibility to cerulein-induced chronic pancreatitis & C57BL/6J (JAX), C57BL/6NHsd (Envigo) & {$[76]$} \\
\hline $\begin{array}{l}\text { Hearing/vestibular/ear } \\
\text { phenotype }\end{array}$ & Susceptibility to aminoglycoside-induced ototoxicity & C57BL/6J (JAX), C57BL/6NHsd (Envigo) & {$[77]$} \\
\hline $\begin{array}{l}\text { Hematopoietic system } \\
\text { phenotype }\end{array}$ & Sensitivity of hematopoietic stem cells to oxidative stress & C57BL/6J (JAX), C57BL/6NCrl (CRL) & {$[78]$} \\
\hline \multirow{12}{*}{$\begin{array}{l}\text { Homeostasis/metabolic } \\
\text { phenotype }\end{array}$} & Clinical chemistry parameters & C57BL/6J (JAX), C57BL/6NTac (TAC) & [79] \\
\hline & Effects of oats on plasma cholesterol and lipoproteins & C57BL/6JBomTac (TAC), C57BL/6NCrl (CRL) & {$[80]$} \\
\hline & Hematological and iron-related parameters & C57BL/6J (JAX), C57BL/6NCrl (CRL) & [81] \\
\hline & Insulin secretory response to high-fat diet & $\begin{array}{l}\text { C57BL/6J (JAX), C57BL/6J (WEHI), } \\
\text { C57BL/6NCrl (CRL), C57BL/6NHsd (Envigo), } \\
\text { C57BL/6NJ (JAX), C57BL/6NTac (TAC) }\end{array}$ & {$[82]$} \\
\hline & Response to intermittent hypoxia & C57BL/6J (JAX), C57BL/6NCrl (CRL) & [83] \\
\hline & Response to diet-induced obesity & C57BL/6JRj (Janvier Labs), C57BL/6NTac (TAC) & {$[84]$} \\
\hline & & C57BL/6JRj (Janvier Labs), C57BL/6NTac (TAC) & {$[85]$} \\
\hline & & C57BL/6J (JAX), C57BL/6NJ (JAX) & [86] \\
\hline & Response to glucose-stimulated insulin secretion & C57BL/6J (JAX), C57BL/6NCrl (CRL) & [87] \\
\hline & Response to high-fat diet & C57BL/6J (JAX), C57BL/6NJ (JAX) & {$[88]$} \\
\hline & & $\begin{array}{l}\text { C57BL/6J (JAX), C57BL/6JBomTac (TAC), } \\
\text { C57BL/6JRj (Janvier Labs) }\end{array}$ & [89] \\
\hline & Skeletal and metabolic responses to high-fat diet & C57BL/6J (JAX), C57BL/6NCrl (CRL) & {$[90]$} \\
\hline \multirow[t]{4}{*}{$\begin{array}{l}\text { Immune system phe- } \\
\text { notype }\end{array}$} & $\begin{array}{l}\text { Neutrophil recruitment in response to inflammatory } \\
\text { stimuli }\end{array}$ & C57BL/6J (JAX), C57BL/6N (NCI) & [91] \\
\hline & Non-ecotropic ERV expression level & C57BL/6J (JAX), C57BL/6NJ (JAX) & [92] \\
\hline & Susceptibility to influenza A virus & C57BL/6J (JAX), C57BL/6NCrl (CRL) & [93] \\
\hline & Susceptibility to Listeria monocytogenes & C57BL/6J (JAX), C57BL/6ByJ (JAX) & [94] \\
\hline Integument phenotype & Sensitivity to Aldara ${ }^{\mathrm{TM}}$-induced psoriasiform dermatitis & $\begin{array}{l}\text { C57BL/6JRj (Janvier Labs), C57BL/6NRj (Janvier } \\
\text { Labs) }\end{array}$ & [95] \\
\hline \multirow{2}{*}{$\begin{array}{l}\text { Liver/biliary system } \\
\text { phenotype }\end{array}$} & Susceptibility to acetaminophen-induced liver injury & C57BL/6J (JAX), C57BL/6NCr (NIH) & [96] \\
\hline & $\begin{array}{l}\text { Susceptibility to } \mathrm{CCl}_{4} \text { - and high-fat diet-induced non- } \\
\text { alcoholic steatohepatitis }\end{array}$ & C57BL/6J (JAX), C57BL/6NCrSlc (Japan SLC) & [97] \\
\hline \multirow[t]{2}{*}{ Neoplasm phenotype } & $\begin{array}{l}\text { Incidence of 1,2-dimethylhydrazine-induced colorectal } \\
\text { tumors }\end{array}$ & $\begin{array}{l}\text { C57BL/6J (JAX), C57BL/6N (NIH), C57BL/6Ha } \\
\text { (Health Research Inc.) }\end{array}$ & [98] \\
\hline & Susceptibility to Ehrlich ascites carcinoma & C57BL/6J (Andreevka), C57BL/6N (Pushchino) & [99] \\
\hline
\end{tabular}


Table 1. (Continued)

\begin{tabular}{|c|c|c|c|}
\hline Phenotype terms & Descriptions and/or tests & C57BL/6 substrains tested & Publication \\
\hline \multirow[t]{6}{*}{$\begin{array}{l}\text { Nervous system } \\
\text { phenotype }\end{array}$} & Degree of stroke vulnerability & $\begin{array}{l}\text { C57BL/6J (JAX), C57BL/6JEiJ (JAX), } \\
\text { C57BL/6NCrl (CRL), C57BL/6NJ (JAX), } \\
\text { C57BL/6NTac (TAC), C57BL/6ByJ (JAX) }\end{array}$ & [100] \\
\hline & $\begin{array}{l}\text { Ectopic distribution of cerebrospinal fluid contacting } \\
\text { neurons }\end{array}$ & C57BL/6J (JAX), C57BL/6NCrl (CRL) & [101] \\
\hline & Hippocampal mossy fiber morphology & $\begin{array}{l}\text { C57BL/6JKun (Nijmegen Univ.), C57BL/6JNmg } \\
\text { (Nijmegen Univ.) }\end{array}$ & [102] \\
\hline & Hippocampal mossy fiber morphology, radial arm maze & $\begin{array}{l}\text { C57BL/6JKun (Nijmegen Univ.), C57BL/6JNmg } \\
\text { (Nijmegen Univ.) }\end{array}$ & [103] \\
\hline & Prevalence of molecular-layer heteropia & $\begin{array}{l}\text { C57BL/6J (JAX), C57BL/6NCrl (CRL), } \\
\text { C57BL/6NCrSim (Simonsen Lab), } \\
\text { C57BL/6NHla (Hilltop Lab.), C57BL/6NHsd } \\
\text { (Envigo), C57BL/6NTac (TAC) }\end{array}$ & [104] \\
\hline & $\begin{array}{l}\text { Susceptibility to scopolamine-induced neuronal impair- } \\
\text { ment }\end{array}$ & $\begin{array}{l}\text { C57BL/6J (Dae Han Bio Link), C57BL/6N (Dae } \\
\text { Han Bio Link) }\end{array}$ & [105] \\
\hline $\begin{array}{l}\text { Renal/urinary system } \\
\text { phenotype }\end{array}$ & Degree of glyoxylate-induced kidney crystal deposition & C57BL/6J (JAX), C57BL/6NCrl (CRL) & [106] \\
\hline \multirow[t]{2}{*}{$\begin{array}{l}\text { Respiratory system } \\
\text { phenotype }\end{array}$} & Airway responsiveness & $\begin{array}{l}\text { C57BL/6J (JAX), C57BL/6NCrl (CRL), } \\
\text { C57BL/6NTac (TAC), C57BL/6NHsd (Envigo), } \\
\text { C57BL/6NCr (NIH) }\end{array}$ & [107] \\
\hline & Response to neonatal hyperoxia-induced lung injury & $\mathrm{C} 57 \mathrm{BL} / 6 \mathrm{~J}, \mathrm{C} 57 \mathrm{BL} / 6 \mathrm{~N}$ & [108] \\
\hline \multirow[t]{2}{*}{ Skeleton phenotype } & $\begin{array}{l}\text { Bone structure and unloading-induced bone loss in } \\
\text { adolescents }\end{array}$ & C57BL/6J (HJAX), C57BL/6NJ (JAX) & [109] \\
\hline & Trabecular bone mass & $\begin{array}{l}\text { C57BL/6J (JAX), C57BL/6JOlaHsd (Envigo), } \\
\text { C57BL/6JRccHsd (Envigo) }\end{array}$ & [110] \\
\hline \multirow[t]{4}{*}{ Vision/eye phenotype } & Constriction during pupillary light response with aging & $\mathrm{C} 57 \mathrm{BL} / 6 \mathrm{~J}, \mathrm{C} 57 \mathrm{BL} / 6 \mathrm{~N}$ & [111] \\
\hline & Ocular dominance plasticity & C57BL/6J (JAX), C57BL/6JOlaHsd (Envigo) & [112] \\
\hline & $\begin{array}{l}\text { Susceptibility to laser-induced choroidal neovasculariza- } \\
\text { tion }\end{array}$ & C57BL/6J (JAX), C57BL/6NTac (TAC) & [113] \\
\hline & Susceptibility to photoreceptor oxidative stress & C57BL/6J (JAX), C57BL/6NCrl (CRL) & [114] \\
\hline $\begin{array}{l}\text { Comprehensive phe- } \\
\text { notype* }\end{array}$ & EMPReSSslim pipelines & C57BL/6J (JAX), C57BL/6NTac (TAC) & [115] \\
\hline
\end{tabular}

The phenotype terms column basically follows the Mammalian Phenotype Ontology [116]. The parentheses to the right of the strain names indicate the vendor or facility where the mice were produced. JAX, The Jackson Laboratory; CRL, Charles River Laboratories; TAC, Taconic Biosciences; WEHI, Walter and Eliza Hall Institute; HZM, Helmholtz Zentrum München; CEMIB, Multidisciplinary Center for Biological Investigation on Laboratory Animal Science, The University of Campinas. Strains without parentheses are those for which information on the vendor or production facility was not included in the publication. *By comprehensive phenotype screening (substrain differences were identified in cardiovascular, hematopoietic, adipose tissue, behavioral/neurological, renal/ urinary, skeletal, hematopoietic, vision/eye, and immune system phenotypes).

\section{Other Phenotypic Differences Among C57BL/6 Substrains}

In addition to the abovementioned cases in which the causative genes were identified, phenotypic differences have been reported among the substrains used to generate the $\mathrm{C} 57 \mathrm{BL} / 6$ congenic strain. Greater improvement in terms of seizure severity and viability was achieved in Dravet syndrome model mice with knockout of the sodium channel, voltage-gated, type I, alpha (Scn1a) gene generated on a $\mathrm{C} 57 \mathrm{BL} / 6 \mathrm{NJ}$ versus $\mathrm{C} 57 \mathrm{BL} / 6 \mathrm{~J}$ background [135]. Obvious phenotypic differences have been demonstrated between C57BL/6J and C57BL/6N substrains, as shown in studies on knockout of the coagulation factor VIII $(F 8)$ and fatty acid binding protein 1, liver $(F a b p 1)$ genes, suggesting the presence of genetic factors that differentially modify phenotypes between the substrains [136, 137]. It has also been demonstrated that tumor cell rejection in E $\mu$-TCL1 transgenic mice, a model of chronic lymphocytic leukemia, is associated with differences between the C57BL/6 substrains, suggesting that acute immune rejection may be mediated by antigens that differ between $\mathrm{C} 57 \mathrm{BL} / 6 \mathrm{~J}$ and $\mathrm{C} 57 \mathrm{BL} / 6 \mathrm{~N}$ mice [138]. In addition, $\mathrm{C} 57 \mathrm{BL} / 6 \mathrm{~J}-\mathrm{XY} \mathrm{POS}^{\mathrm{P}}$ congenic mice, which have a $\mathrm{Y}$ chromosome derived from Mus musculus poschiavinus on a C57BL/6J genetic background, form ovotestes or ovaries [139, 140]. Changing from a C57BL/6J to C57BL/6N background increases the likelihood of testis-forming individuals, suggesting that genetic differences involved in the regulation of the sex determining region of Chr Y (Sry) and the SRY (sex determining region Y)-box 9 (Sox9) gene expression, which play an important role in testicular differentiation, exist between the C57BL/6J and N substrains [141, 142]. 
Table 2. Genetic or genomic structural variations affecting phenotypes among C57BL/6 substrains

\begin{tabular}{|c|c|c|}
\hline Strain name & Reported genetic or genomic variations & Affected phenotypes \\
\hline $\begin{array}{l}\text { C57BL/6 (JAX), C57BL/6JJcl (CLEA Japan), } \\
\text { C57BL/6JJmsSlc (Japan SLC), C57BL/6JMs } \\
\text { (National Institute of Genetics) }\end{array}$ & $\begin{array}{l}17,814 \text { bp deletion between exons } 6 \text { and } \\
12 \text {, which corresponds to exons } 7-11 \text { of } \\
\text { the } N n t \text { gene }[117,118] \text {. }\end{array}$ & $\begin{array}{l}\text { Abnormal glucose tolerance and } \\
\text { impaired insulin secretion }\end{array}$ \\
\hline C57BL/6JOlaHsd (Envigo) & $\begin{array}{l}365 \mathrm{~kb} \text { spontaneous deletion of chromo- } \\
\text { some } 6 \text {, including the Snca and Mmrn1 } \\
\text { genes }[119,120] .\end{array}$ & $\begin{array}{l}\text { No significant effects on brain } \\
\text { structure or composition, but may } \\
\text { affect motor neuron degeneration and } \\
\text { trabecular bone mass }\end{array}$ \\
\hline $\begin{array}{l}\text { All C57BL/6N substrains, including } \\
\text { C57BL/6ByJ (JAX) and C57BL/6JBy (JAX) }\end{array}$ & $\begin{array}{l}\text { Single base deletion of the } \mathrm{Crbl} \text { gene, } \\
\text { causing a frameshift and premature stop } \\
\text { codon which truncates the transmembrane } \\
\text { and cytoplasmic domain of the protein } \\
{[121,122] \text {. }}\end{array}$ & $\begin{array}{l}\text { Typical lesions of rd8 retinal degen- } \\
\text { eration }\end{array}$ \\
\hline C57BL/6NHsd (Envigo) & $\begin{array}{l}\text { Genomic duplication of exons } 28 \text { and } 29 \\
\text { and a frameshift mutation after exon } 29 \text { in } \\
\text { the Dock } 2 \text { gene }[123,124] \text {. }\end{array}$ & $\begin{array}{l}\text { Affected B cell signaling and immune } \\
\text { tolerance }\end{array}$ \\
\hline C57BL/6JBomTac (TAC) & $\begin{array}{l}40 \mathrm{Mb} \text {-long deletion between } 6.12 / 6.57 \\
\text { and } 46.73 / 47.31 \mathrm{Mb} \text { on the } \mathrm{Y} \text { chromosome } \\
\text { long arm [125]. }\end{array}$ & $\begin{array}{l}\text { Increased rate of sperm morpho- } \\
\text { logical abnormalities, unbalanced sex } \\
\text { ratio, and dysregulation of several } \\
\text { transcripts expressed in the testes }\end{array}$ \\
\hline
\end{tabular}

The parentheses to the right of the strain names indicate the vendor or facility where the mice were produced. JAX, The Jackson Laboratory; TAC, Taconic Biosciences.

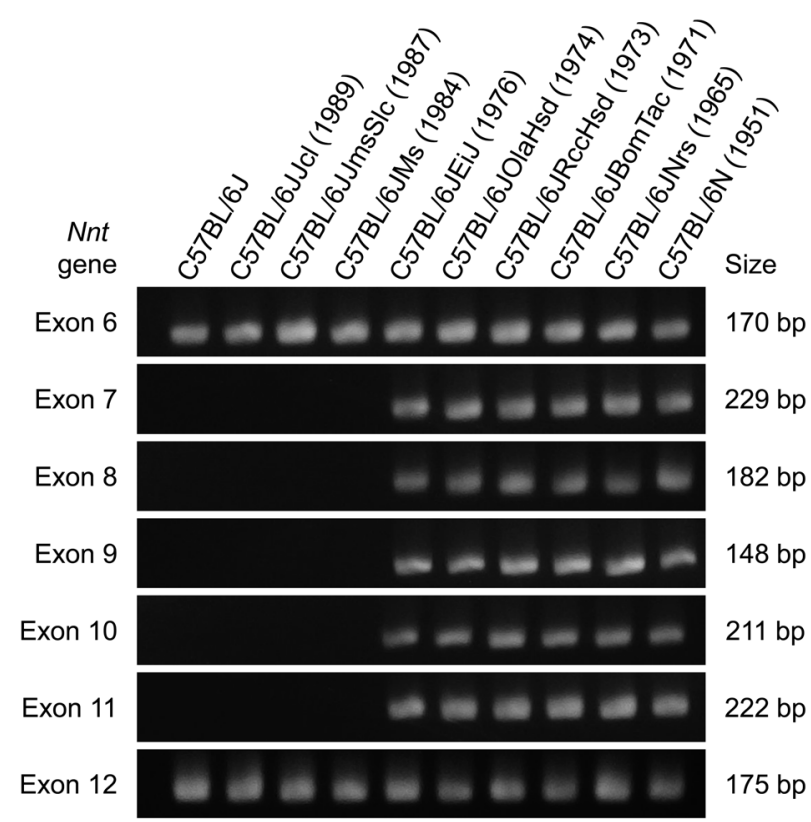

Fig. 3. The deletion of exons $7-11$ in the $N n t$ gene of C57BL/6J substrains. Genomic polymerase chain reaction $(\mathrm{PCR})$ analysis of exons 6-12 in the Nnt gene showed the absence of PCR products from exons $7-11$ in the $\mathrm{C} 57 \mathrm{BL} / 6 \mathrm{~J}$, C57BL/6JJcl, C57BL/6JJmsSlc, and C57BL/6JMs substrains. The deletion of the Nnt gene occurred in the C57BL/6J colony of the Jackson Laboratory between 1976 and 1984. The branching years of each strain from the original $\mathrm{C} 57 \mathrm{BL} / 6 \mathrm{~J}$ strain are given in parentheses. PCR and gel electrophoresis procedures were performed according to the protocol described in Mekada et al. (2009) [6]. PCR product size data are from Huang et al. (2006) [117].
Differences in prevalence of sexual dimorphism among C57BL/6 substrains should also be considered. Significant variation in brain injuries has been reported among C57BL/6 substrains [69, 143]. In mouse stroke, male and female $\mathrm{C} 57 \mathrm{BL} / 6 \mathrm{~N}$ mice show similar infarct sizes, although female $\mathrm{C} 57 \mathrm{BL} / 6 \mathrm{~J}$ mice tend to have smaller infarcts [100]. Such substrain-specific sexual dimorphisms have also been identified in analyses of behavioral characteristics, serum biochemistry, and immune function $[36,79,115]$. Therefore, in studies of the effects of genetic modifications on sex differences, heterogeneity in substrain backgrounds would likely complicate the interpretation of experimental results. Thus, the phenotypic differences among C57BL/6 substrains are quite numerous, and they should be reported more in the future.

\section{Genetic Polymorphisms in C57BL/6 J Substrains}

Single nucleotide polymorphisms (SNPs) are the most widely used genetic markers in genomes and are useful for uncovering genetic differences between genetically similar lineages, including substrains. In laboratory mouse strains, SNP databases have been developed by mapping sequence data from other inbred lines using the Jackson Laboratory's C57BL/6J strain as a reference [144-149]. SNPs that distinguish each C57BL/6J substrain can be extracted from candidates specific to the C57BL/6J strain in SNP databases as well as by identify- 
ing the genotypes of candidate SNP loci for each C57BL/6J substrain [6, 150-152]. In Table 3, genotypes of $\mathrm{C} 57 \mathrm{BL} / 6 \mathrm{~J}$ substrains and the $\mathrm{C} 57 \mathrm{BL} / 6 \mathrm{~N}$ strain at 45 SNP loci are shown in chronological order with $\mathrm{C} 57 \mathrm{BL} / 6 \mathrm{~N}$ at the bottom and eight $\mathrm{C} 57 \mathrm{BL} / 6 \mathrm{~J}$ substrains and the current $\mathrm{C} 57 \mathrm{BL} / 6 \mathrm{~J}$ strain at the top. This table clearly indicates that the ancestral-type SNPs (shaded in blue) of $\mathrm{C} 57 \mathrm{BL} / 6 \mathrm{~J}$ and $\mathrm{N}$ (as represented by the C57BL/6N strain) have decreased and been replaced by the C57BL/6J-type SNPs at the 23 loci (shaded in red) since 1951. The SNPs are considered to have occurred and accumulated in the original C57BL/6J strain. Since the SNP genotype pattern of each substrain branched at different years is distinct, these SNP loci genotypes can be used to distinguish every C57BL/6J substrain available in the research community.

The lymphocyte antigen $5(L y 5)$ congenic strain is a representative mouse strain derived from the $\mathrm{C} 57 \mathrm{BL} / 6 \mathrm{~J}$ substrain. The lymphoid cell surface antigen produced by the protein tyrosine phosphatase, receptor type, $\mathrm{C}$ (Ptprc; Ly5/Cd45 gene) gene distinguishes between hematopoietic cells from donor and recipient mice; hence, this strain has been widely used as a cell marker for bone marrow transplantation studies $[153,154]$. The C57BL/6Ly5.1 congenic inbred strain (B6JBoy.SJL-Ptptc ${ }^{a}$; RBRC00144) was established by Boyes et al. at SloanKettering Institute through introduction of the $L y 5.1$ of the SJL/J strain into the C57BL/6JBoy strain background

Table 3. Single nucleotide polymorphisms (SNPs) in C57BL/6J substrains

\begin{tabular}{|c|c|c|c|c|c|c|c|c|c|c|c|c|c|c|c|c|c|}
\hline \multirow{2}{*}{ Strain name } & \multirow{2}{*}{$\begin{array}{l}\text { Branching } \\
\text { year* }\end{array}$} & \multirow{2}{*}{$\begin{array}{c}\text { No. of C57BL/6 } \\
\text { ancestral-type } \\
\text { SNPs }\end{array}$} & \multicolumn{15}{|c|}{ Locus No. ${ }^{\dagger}$} \\
\hline & & & 1 & 2 & 3 & 4 & 5 & 6 & 7 & 8 & 9 & 10 & 11 & 12 & 13 & 14 & 15 \\
\hline $57 \mathrm{BL} / 6 \mathrm{~J}$ & & 0 & $\mathrm{~T} / \mathrm{T}$ & $\mathrm{A} / \mathrm{A}$ & $\mathrm{G} / \mathrm{G}$ & $\mathrm{A} / \mathrm{A}$ & $\mathrm{C} / \mathrm{C}$ & $\mathrm{T} / \mathrm{T}$ & $\mathrm{G} / \mathrm{G}$ & $\mathrm{T} / \mathrm{T}$ & $\mathrm{T} / \mathrm{T}$ & $\mathrm{C} / \mathrm{C}$ & $\mathrm{A} / \mathrm{A}$ & $\mathrm{T} / \mathrm{T}$ & $\mathrm{T} / \mathrm{T}$ & $\mathrm{A} / \mathrm{A}$ & $\mathrm{T} / \mathrm{T}$ \\
\hline C57BI & 1989 & 3 & $\mathrm{~T} / \mathrm{T}$ & $\mathrm{A} / \mathrm{A}$ & $\mathrm{A} / \mathrm{A}$ & $\mathrm{A} / \mathrm{A}$ & $\mathrm{C} / \mathrm{C}$ & $\mathrm{A} / \mathrm{A}$ & $\mathrm{G} / \mathrm{G}$ & $\mathrm{T} / \mathrm{T}$ & $\mathrm{T} / \mathrm{T}$ & $\mathrm{C} / \mathrm{C}$ & $\mathrm{A} / \mathrm{A}$ & $\mathrm{T} / \mathrm{T}$ & $\mathrm{T} / \mathrm{T}$ & $\mathrm{A} / \mathrm{A}$ & $\mathrm{T} / \mathrm{T}$ \\
\hline C57BL/6JJmsSlc & 1987 & 5 & $\mathrm{~T} / \mathrm{T}$ & $\mathrm{A} / \mathrm{A}$ & $\mathrm{A} / \mathrm{A}$ & $\mathrm{A} / \mathrm{A}$ & $\mathrm{C} / \mathrm{C}$ & $\mathrm{A} / \mathrm{A}$ & $\mathrm{G} / \mathrm{G}$ & $\mathrm{T} / \mathrm{T}$ & $\mathrm{T} / \mathrm{T}$ & $\mathrm{C} / \mathrm{C}$ & $\mathrm{A} / \mathrm{A}$ & $\mathrm{C} / \mathrm{C}$ & $\mathrm{T} / \mathrm{T}$ & $\mathrm{A} / \mathrm{A}$ & $\mathrm{T} / \mathrm{T}$ \\
\hline & 1 & 7 & $\mathrm{~T} / \mathrm{T}$ & $\mathrm{A} / \mathrm{A}$ & $\mathrm{A} / \mathrm{A}$ & $\mathrm{C} / \mathrm{C}$ & $\mathrm{C} / \mathrm{C}$ & $\mathrm{A} / \mathrm{A}$ & $\mathrm{G} / \mathrm{G}$ & $\mathrm{T} / \mathrm{T}$ & $\mathrm{T} / \mathrm{T}$ & $\mathrm{C} / \mathrm{C}$ & $\mathrm{A} / \mathrm{A}$ & $\mathrm{C} / \mathrm{C}$ & $\mathrm{T} / \mathrm{T}$ & $\mathrm{A} / \mathrm{A}$ & $\mathrm{T} / \mathrm{T}$ \\
\hline $\mathrm{C5}$ & 1976 & 13 & $\mathrm{~T} / \mathrm{T}$ & $\mathrm{A} / \mathrm{A}$ & $\mathrm{A} / \mathrm{A}$ & $\mathrm{C} / \mathrm{C}$ & $\mathrm{C} / \mathrm{C}$ & $\mathrm{A} / \mathrm{A}$ & $\mathrm{G} / \mathrm{G}$ & $\mathrm{T} / \mathrm{T}$ & $\mathrm{T} / \mathrm{T}$ & $\mathrm{C} / \mathrm{C}$ & $\mathrm{A} / \mathrm{A}$ & $\mathrm{C} / \mathrm{C}$ & $\mathrm{T} / \mathrm{T}$ & $\mathrm{A} / \mathrm{A}$ & $\mathrm{T} / \mathrm{T}$ \\
\hline C57. & 19 & 14 & $\mathrm{~T} / \mathrm{T}$ & $\mathrm{A} / \mathrm{A}$ & $\mathrm{A} / \mathrm{A}$ & $\mathrm{C} / \mathrm{C}$ & $\mathrm{C} / \mathrm{C}$ & $\mathrm{A} / \mathrm{A}$ & $\mathrm{C} / \mathrm{C}$ & $\mathrm{T} / \mathrm{T}$ & $\mathrm{T} / \mathrm{T}$ & $\mathrm{C} / \mathrm{C}$ & $\mathrm{A} / \mathrm{A}$ & $\mathrm{C} / \mathrm{C}$ & $\mathrm{T} / \mathrm{T}$ & $\mathrm{A} / \mathrm{A}$ & $\mathrm{T} / \mathrm{T}$ \\
\hline C57BL $/ 6$ & 1973 & 14 & $\mathrm{~T} / \mathrm{T}$ & $\mathrm{A} / \mathrm{A}$ & $\mathrm{A} / \mathrm{A}$ & $\mathrm{C} / \mathrm{C}$ & $\mathrm{C} / \mathrm{C}$ & $\mathrm{A} / \mathrm{A}$ & $\mathrm{C} / \mathrm{C}$ & $\mathrm{T} / \mathrm{T}$ & $\mathrm{T} / \mathrm{T}$ & $\mathrm{C} / \mathrm{C}$ & $\mathrm{A} / \mathrm{A}$ & $\mathrm{C} / \mathrm{C}$ & $\mathrm{T} / \mathrm{T}$ & $\mathrm{A} / \mathrm{A}$ & $\mathrm{T} / \mathrm{T}$ \\
\hline C57BL/6JBomTac & 1971 & 17 & $\mathrm{~T} / \mathrm{T}$ & $\mathrm{T} / \mathrm{T}$ & $\mathrm{A} / \mathrm{A}$ & $\mathrm{C} / \mathrm{C}$ & $\mathrm{C} / \mathrm{C}$ & $\mathrm{A} / \mathrm{A}$ & $\mathrm{C} / \mathrm{C}$ & $\mathrm{T} / \mathrm{T}$ & $\mathrm{T} / \mathrm{T}$ & $\mathrm{C} / \mathrm{C}$ & $\mathrm{A} / \mathrm{A}$ & $\mathrm{C} / \mathrm{C}$ & $\mathrm{T} / \mathrm{T}$ & $\mathrm{A} / \mathrm{A}$ & $\mathrm{A} / \mathrm{A}$ \\
\hline C57BL/6JNrs & 1965 & 23 & $\mathrm{~T} / \mathrm{T}$ & $\mathrm{T} / \mathrm{T}$ & $\mathrm{A} / \mathrm{A}$ & $\mathrm{C} / \mathrm{C}$ & $\mathrm{T} / \mathrm{T}$ & $\mathrm{A} / \mathrm{A}$ & $\mathrm{C} / \mathrm{C}$ & $\mathrm{C} / \mathrm{C}$ & $\mathrm{T} / \mathrm{T}$ & $\mathrm{C} / \mathrm{C}$ & $\mathrm{A} / \mathrm{A}$ & $\mathrm{C} / \mathrm{C}$ & $\mathrm{T} / \mathrm{T}$ & $\mathrm{A} / \mathrm{A}$ & $\mathrm{A} / \mathrm{A}$ \\
\hline C57BL/6N substrains & 1951 & 45 & $\mathrm{C} / \mathrm{C}$ & $\mathrm{T} / \mathrm{T}$ & $\mathrm{A} / \mathrm{A}$ & $\mathrm{C} / \mathrm{C}$ & $\mathrm{T} / \mathrm{T}$ & $\mathrm{A} / \mathrm{A}$ & $\mathrm{C} / \mathrm{C}$ & $\mathrm{C} / \mathrm{C}$ & $\mathrm{C} / \mathrm{C}$ & $\mathrm{A} / \mathrm{A}$ & $\mathrm{G} / \mathrm{G}$ & $\mathrm{C} / \mathrm{C}$ & $\mathrm{A} / \mathrm{A}$ & $\mathrm{G} / \mathrm{G}$ & $\mathrm{A} / \mathrm{A}$ \\
\hline
\end{tabular}

\begin{tabular}{|c|c|c|c|c|c|c|c|c|c|c|c|c|c|c|c|c|c|}
\hline \multirow{2}{*}{ Strain name } & \multirow{2}{*}{$\begin{array}{c}\text { Branching } \\
\text { year* }\end{array}$} & \multirow{2}{*}{$\begin{array}{c}\text { No. of C57BL/6 } \\
\text { ancestral-type } \\
\text { SNPs }\end{array}$} & \multicolumn{15}{|c|}{ Locus No. $^{\dagger}$} \\
\hline & & & 16 & 17 & 18 & 19 & 20 & 21 & 22 & 23 & 24 & 25 & 26 & 27 & 28 & 29 & 30 \\
\hline $\mathrm{C} 57 \mathrm{BL} / 6 \mathrm{~J}$ & & 0 & $\mathrm{~A} / \mathrm{A}$ & $\mathrm{A} / \mathrm{A}$ & $\mathrm{T} / \mathrm{T}$ & $\mathrm{T} / \mathrm{T}$ & $\mathrm{A} / \mathrm{A}$ & $\mathrm{T} / \mathrm{T}$ & $\mathrm{T} / \mathrm{T}$ & $\mathrm{T} / \mathrm{T}$ & $\mathrm{G} / \mathrm{G}$ & $\mathrm{T} / \mathrm{T}$ & $\mathrm{T} / \mathrm{T}$ & $\mathrm{C} / \mathrm{C}$ & $\mathrm{G} / \mathrm{G}$ & $\mathrm{T} / \mathrm{T}$ & $\mathrm{G} / \mathrm{G}$ \\
\hline C57BL/6JJcl & 1989 & 3 & $\mathrm{~A} / \mathrm{A}$ & $\mathrm{A} / \mathrm{A}$ & $\mathrm{T} / \mathrm{T}$ & $\mathrm{T} / \mathrm{T}$ & $\mathrm{A} / \mathrm{A}$ & $\mathrm{T} / \mathrm{T}$ & $\mathrm{T} / \mathrm{T}$ & $\mathrm{T} / \mathrm{T}$ & $\mathrm{G} / \mathrm{G}$ & $\mathrm{T} / \mathrm{T}$ & $\mathrm{T} / \mathrm{T}$ & $\mathrm{C} / \mathrm{C}$ & $\mathrm{G} / \mathrm{G}$ & $\mathrm{T} / \mathrm{T}$ & $\mathrm{G} / \mathrm{G}$ \\
\hline C57BL/6JJmsSlc & 1987 & 5 & $\mathrm{~A} / \mathrm{A}$ & $\mathrm{A} / \mathrm{A}$ & $\mathrm{T} / \mathrm{T}$ & $\mathrm{T} / \mathrm{T}$ & $\mathrm{A} / \mathrm{A}$ & $\mathrm{T} / \mathrm{T}$ & $\mathrm{T} / \mathrm{T}$ & $\mathrm{T} / \mathrm{T}$ & $\mathrm{G} / \mathrm{G}$ & $\mathrm{T} / \mathrm{T}$ & $\mathrm{T} / \mathrm{T}$ & $\mathrm{C} / \mathrm{C}$ & $\mathrm{G} / \mathrm{G}$ & $\mathrm{T} / \mathrm{T}$ & $\mathrm{G} / \mathrm{G}$ \\
\hline C57BL/6JMs & 1984 & 7 & $\mathrm{~A} / \mathrm{A}$ & $\mathrm{A} / \mathrm{A}$ & $\mathrm{T} / \mathrm{T}$ & $\mathrm{C} / \mathrm{C}$ & $\mathrm{A} / \mathrm{A}$ & $\mathrm{T} / \mathrm{T}$ & $\mathrm{T} / \mathrm{T}$ & $\mathrm{T} / \mathrm{T}$ & $\mathrm{G} / \mathrm{G}$ & $\mathrm{T} / \mathrm{T}$ & $\mathrm{T} / \mathrm{T}$ & $\mathrm{C} / \mathrm{C}$ & $\mathrm{G} / \mathrm{G}$ & $\mathrm{T} / \mathrm{T}$ & $\mathrm{G} / \mathrm{G}$ \\
\hline C57BL/6JEiJ & 1976 & 13 & $\mathrm{~A} / \mathrm{A}$ & $\mathrm{A} / \mathrm{A}$ & $\mathrm{C} / \mathrm{C}$ & $\mathrm{C} / \mathrm{C}$ & $\mathrm{A} / \mathrm{A}$ & $\mathrm{T} / \mathrm{T}$ & $\mathrm{T} / \mathrm{T}$ & $\mathrm{T} / \mathrm{T}$ & $\mathrm{G} / \mathrm{G}$ & $\mathrm{T} / \mathrm{T}$ & $\mathrm{T} / \mathrm{T}$ & $\mathrm{C} / \mathrm{C}$ & $\mathrm{G} / \mathrm{G}$ & $\mathrm{T} / \mathrm{T}$ & $\mathrm{G} / \mathrm{G}$ \\
\hline C57BL/6JOlaHsd & 1974 & 14 & $\mathrm{~A} / \mathrm{A}$ & $\mathrm{A} / \mathrm{A}$ & $\mathrm{C} / \mathrm{C}$ & $\mathrm{C} / \mathrm{C}$ & $\mathrm{A} / \mathrm{A}$ & $\mathrm{T} / \mathrm{T}$ & $\mathrm{T} / \mathrm{T}$ & $\mathrm{T} / \mathrm{T}$ & $\mathrm{G} / \mathrm{G}$ & $\mathrm{T} / \mathrm{T}$ & $\mathrm{T} / \mathrm{T}$ & $\mathrm{C} / \mathrm{C}$ & $\mathrm{G} / \mathrm{G}$ & $\mathrm{T} / \mathrm{T}$ & $\mathrm{G} / \mathrm{G}$ \\
\hline C57BL/6JRccHsd & 1973 & 14 & $\mathrm{~A} / \mathrm{A}$ & $\mathrm{A} / \mathrm{A}$ & $\mathrm{C} / \mathrm{C}$ & $\mathrm{C} / \mathrm{C}$ & $\mathrm{A} / \mathrm{A}$ & $\mathrm{T} / \mathrm{T}$ & $\mathrm{T} / \mathrm{T}$ & $\mathrm{T} / \mathrm{T}$ & $\mathrm{G} / \mathrm{G}$ & $\mathrm{T} / \mathrm{T}$ & $\mathrm{T} / \mathrm{T}$ & $\mathrm{C} / \mathrm{C}$ & $\mathrm{G} / \mathrm{G}$ & $\mathrm{T} / \mathrm{T}$ & $\mathrm{G} / \mathrm{G}$ \\
\hline C57BL/6JBomTac & 1971 & 17 & $\mathrm{~A} / \mathrm{A}$ & $\mathrm{A} / \mathrm{A}$ & $\mathrm{C} / \mathrm{C}$ & $\mathrm{C} / \mathrm{C}$ & $\mathrm{A} / \mathrm{A}$ & $\mathrm{T} / \mathrm{T}$ & $\mathrm{T} / \mathrm{T}$ & $\mathrm{T} / \mathrm{T}$ & $\mathrm{G} / \mathrm{G}$ & $\mathrm{C} / \mathrm{C}$ & $\mathrm{T} / \mathrm{T}$ & $\mathrm{C} / \mathrm{C}$ & $\mathrm{G} / \mathrm{G}$ & $\mathrm{T} / \mathrm{T}$ & $\mathrm{G} / \mathrm{G}$ \\
\hline C57BL/6JNrs & 1965 & 23 & $\mathrm{~A} / \mathrm{A}$ & $\mathrm{G} / \mathrm{G}$ & $\mathrm{C} / \mathrm{C}$ & $\mathrm{C} / \mathrm{C}$ & $\mathrm{A} / \mathrm{A}$ & $\mathrm{T} / \mathrm{T}$ & $\mathrm{T} / \mathrm{T}$ & $\mathrm{T} / \mathrm{T}$ & $\mathrm{G} / \mathrm{G}$ & $\mathrm{C} / \mathrm{C}$ & $\mathrm{T} / \mathrm{T}$ & $\mathrm{C} / \mathrm{C}$ & $\mathrm{G} / \mathrm{G}$ & $\mathrm{T} / \mathrm{T}$ & $\mathrm{G} / \mathrm{G}$ \\
\hline $\mathrm{C} 57 \mathrm{BL} / 6 \mathrm{~N}$ substrains & 1951 & 45 & $\mathrm{G} / \mathrm{G}$ & $\mathrm{G} / \mathrm{G}$ & $\mathrm{C} / \mathrm{C}$ & $\mathrm{C} / \mathrm{C}$ & $\mathrm{G} / \mathrm{G}$ & $\mathrm{C} / \mathrm{C}$ & $\mathrm{C} / \mathrm{C}$ & $\mathrm{C} / \mathrm{C}$ & $\mathrm{A} / \mathrm{A}$ & $\mathrm{C} / \mathrm{C}$ & $\mathrm{A} / \mathrm{A}$ & $\mathrm{T} / \mathrm{T}$ & $\mathrm{A} / \mathrm{A}$ & $\mathrm{C} / \mathrm{C}$ & $\mathrm{T} / \mathrm{T}$ \\
\hline
\end{tabular}

\begin{tabular}{|c|c|c|c|c|c|c|c|c|c|c|c|c|c|c|c|c|c|}
\hline \multirow{2}{*}{ Strain name } & \multirow{2}{*}{$\begin{array}{c}\text { Branching } \\
\text { year* }\end{array}$} & \multirow{2}{*}{$\begin{array}{c}\text { No. of C57BL/6 } \\
\text { ancestral-type } \\
\text { SNPs }\end{array}$} & \multicolumn{15}{|c|}{ Locus No. ${ }^{\dagger}$} \\
\hline & & & 31 & 32 & 33 & 34 & 35 & 36 & 37 & 38 & 39 & 40 & 41 & 42 & 43 & 44 & 45 \\
\hline C57BL/6J & & 0 & $\mathrm{G} / \mathrm{G}$ & $\mathrm{A} / \mathrm{A}$ & $\mathrm{T} / \mathrm{T}$ & $\mathrm{G} / \mathrm{G}$ & $\mathrm{A} / \mathrm{A}$ & $\mathrm{A} / \mathrm{A}$ & $\mathrm{A} / \mathrm{A}$ & $\mathrm{T} / \mathrm{T}$ & $\mathrm{C} / \mathrm{C}$ & $\mathrm{A} / \mathrm{A}$ & $\mathrm{T} / \mathrm{T}$ & $\mathrm{T} / \mathrm{T}$ & $\mathrm{G} / \mathrm{G}$ & $\mathrm{G} / \mathrm{G}$ & $\mathrm{A} / \mathrm{A}$ \\
\hline C57BL/6JJcl & 1989 & 3 & $\mathrm{~A} / \mathrm{A}$ & $\mathrm{A} / \mathrm{A}$ & $\mathrm{T} / \mathrm{T}$ & $\mathrm{G} / \mathrm{G}$ & $\mathrm{A} / \mathrm{A}$ & $\mathrm{A} / \mathrm{A}$ & $\mathrm{A} / \mathrm{A}$ & $\mathrm{T} / \mathrm{T}$ & $\mathrm{C} / \mathrm{C}$ & $\mathrm{A} / \mathrm{A}$ & $\mathrm{T} / \mathrm{T}$ & $\mathrm{T} / \mathrm{T}$ & $\mathrm{G} / \mathrm{G}$ & $\mathrm{G} / \mathrm{G}$ & $\mathrm{A} / \mathrm{A}$ \\
\hline C57BL/6JJmsSlc & 1987 & 5 & $\mathrm{~A} / \mathrm{A}$ & $\mathrm{A} / \mathrm{A}$ & $\mathrm{T} / \mathrm{T}$ & $\mathrm{G} / \mathrm{G}$ & $\mathrm{A} / \mathrm{A}$ & $\mathrm{A} / \mathrm{A}$ & $\mathrm{A} / \mathrm{A}$ & $\mathrm{T} / \mathrm{T}$ & $\mathrm{C} / \mathrm{C}$ & $\mathrm{A} / \mathrm{A}$ & $\mathrm{T} / \mathrm{T}$ & $\mathrm{T} / \mathrm{T}$ & $\mathrm{G} / \mathrm{G}$ & $\mathrm{G} / \mathrm{G}$ & $\mathrm{T} / \mathrm{T}$ \\
\hline C57BL/6JMs & 1984 & 7 & $\mathrm{~A} / \mathrm{A}$ & $\mathrm{A} / \mathrm{A}$ & $\mathrm{T} / \mathrm{T}$ & $\mathrm{G} / \mathrm{G}$ & $\mathrm{A} / \mathrm{A}$ & $\mathrm{A} / \mathrm{A}$ & $\mathrm{A} / \mathrm{A}$ & $\mathrm{T} / \mathrm{T}$ & $\mathrm{C} / \mathrm{C}$ & $\mathrm{A} / \mathrm{A}$ & $\mathrm{T} / \mathrm{T}$ & $\mathrm{T} / \mathrm{T}$ & $\mathrm{G} / \mathrm{G}$ & $\mathrm{G} / \mathrm{G}$ & $\mathrm{T} / \mathrm{T}$ \\
\hline C57BL/6JEiJ & 1976 & 13 & $\mathrm{~A} / \mathrm{A}$ & $\mathrm{A} / \mathrm{A}$ & $\mathrm{A} / \mathrm{A}$ & $\mathrm{G} / \mathrm{G}$ & $\mathrm{C} / \mathrm{C}$ & $\mathrm{A} / \mathrm{A}$ & $\mathrm{G} / \mathrm{G}$ & $\mathrm{T} / \mathrm{T}$ & $\mathrm{C} / \mathrm{C}$ & $\mathrm{A} / \mathrm{A}$ & $\mathrm{T} / \mathrm{T}$ & $\mathrm{C} / \mathrm{C}$ & $\mathrm{G} / \mathrm{G}$ & $\mathrm{T} / \mathrm{T}$ & $\mathrm{T} / \mathrm{T}$ \\
\hline C57BL/6JOlaHsd & 1974 & 14 & $\mathrm{~A} / \mathrm{A}$ & $\mathrm{A} / \mathrm{A}$ & $\mathrm{A} / \mathrm{A}$ & $\mathrm{G} / \mathrm{G}$ & $\mathrm{C} / \mathrm{C}$ & $\mathrm{A} / \mathrm{A}$ & $\mathrm{G} / \mathrm{G}$ & $\mathrm{T} / \mathrm{T}$ & $\mathrm{C} / \mathrm{C}$ & $\mathrm{A} / \mathrm{A}$ & $\mathrm{T} / \mathrm{T}$ & $\mathrm{C} / \mathrm{C}$ & $\mathrm{G} / \mathrm{G}$ & $\mathrm{T} / \mathrm{T}$ & $\mathrm{T} / \mathrm{T}$ \\
\hline C57BL/6JRccHsd & 1973 & 14 & $\mathrm{~A} / \mathrm{A}$ & $\mathrm{A} / \mathrm{A}$ & $\mathrm{A} / \mathrm{A}$ & $\mathrm{G} / \mathrm{G}$ & $\mathrm{C} / \mathrm{C}$ & $\mathrm{A} / \mathrm{A}$ & $\mathrm{G} / \mathrm{G}$ & $\mathrm{T} / \mathrm{T}$ & $\mathrm{C} / \mathrm{C}$ & $\mathrm{A} / \mathrm{A}$ & $\mathrm{T} / \mathrm{T}$ & $\mathrm{C} / \mathrm{C}$ & $\mathrm{G} / \mathrm{G}$ & $\mathrm{T} / \mathrm{T}$ & $\mathrm{T} / \mathrm{T}$ \\
\hline C57BL/6JBomTac & 1971 & 17 & $\mathrm{~A} / \mathrm{A}$ & $\mathrm{A} / \mathrm{A}$ & $\mathrm{A} / \mathrm{A}$ & $\mathrm{G} / \mathrm{G}$ & $\mathrm{C} / \mathrm{C}$ & $\mathrm{A} / \mathrm{A}$ & $\mathrm{G} / \mathrm{G}$ & $\mathrm{T} / \mathrm{T}$ & $\mathrm{C} / \mathrm{C}$ & $\mathrm{A} / \mathrm{A}$ & $\mathrm{T} / \mathrm{T}$ & $\mathrm{C} / \mathrm{C}$ & $\mathrm{G} / \mathrm{G}$ & $\mathrm{T} / \mathrm{T}$ & $\mathrm{T} / \mathrm{T}$ \\
\hline C57BL/6JNrs & 1965 & 23 & $\mathrm{~A} / \mathrm{A}$ & $\mathrm{A} / \mathrm{A}$ & $\mathrm{A} / \mathrm{A}$ & $\mathrm{G} / \mathrm{G}$ & $\mathrm{C} / \mathrm{C}$ & $\mathrm{A} / \mathrm{A}$ & $\mathrm{G} / \mathrm{G}$ & $\mathrm{T} / \mathrm{T}$ & $\mathrm{T} / \mathrm{T}$ & $\mathrm{G} / \mathrm{G}$ & $\mathrm{T} / \mathrm{T}$ & $\mathrm{C} / \mathrm{C}$ & $\mathrm{C} / \mathrm{C}$ & $\mathrm{T} / \mathrm{T}$ & $\mathrm{T} / \mathrm{T}$ \\
\hline C57BL/6N substrains & 1951 & 45 & $\mathrm{~A} / \mathrm{A}$ & $\mathrm{G} / \mathrm{G}$ & $\mathrm{A} / \mathrm{A}$ & $\mathrm{A} / \mathrm{A}$ & $\mathrm{C} / \mathrm{C}$ & $\mathrm{G} / \mathrm{G}$ & $\mathrm{G} / \mathrm{G}$ & $\mathrm{C} / \mathrm{C}$ & $\mathrm{T} / \mathrm{T}$ & $\mathrm{G} / \mathrm{G}$ & $\mathrm{C} / \mathrm{C}$ & $\mathrm{C} / \mathrm{C}$ & $\mathrm{C} / \mathrm{C}$ & $\mathrm{T} / \mathrm{T}$ & $\mathrm{T} / \mathrm{T}$ \\
\hline
\end{tabular}

*The year in which each C57BL/6 substrain branched from the C57BL/6J strain of the Jackson Laboratory. ${ }^{\dagger}$ Corresponds to Locus No. in Supplementary Table 2. The genotypes of all SNP loci were identical among the C57BL/6N substrains, including C57BL/6NTac, C57BL/6NHsd, C57BL/6NJ, C57BL/6Seac, C57BL/6NJcl, C57BL/6NCrSim, C57BL/6NCrlCrlj, C57BL/6NCrl, C57BL/6NCrSlc, C57BL/6ByJ, and C57BL/By. 
(Ly5.2 allele) by 23 serial backcrosses $[155,156]$. The exact point at which the $\mathrm{C} 57 \mathrm{BL} / 6 \mathrm{JB}$ oy strain diverged from the $\mathrm{C} 57 \mathrm{BL} / 6 \mathrm{~J}$ strain is not clear, but the literature suggests that divergence occurred in the 1970s, or possibly even earlier [157]. According to genetic background testing using C57BL/6J-specific SNP markers, the genetic background should be similar to that of older C57BL/6J substrains, which have an earlier divergence date (Table 4). Although C57BL/6-Ly5 antigen congenic mice are currently available from several vendors, a spontaneous mutation in the natural cytotoxicity triggering receptor 1 ( Ncrl) locus and residual chromosomal fragments of the donor SJL/J strain, both of which affect immune response, have been reported $[158,159]$. These effects must be considered to properly interpret the results of experiments involving these strains $[158,159]$.

\section{Genetic Polymorphisms in C57BL/6N Substrains}

In the $\mathrm{C} 57 \mathrm{BL} / 6 \mathrm{~N}$ substrain, genotyping of the above C57BL/6J-specific SNP loci could not detect polymorphism as observed in C57BL/6J [6]. This is because the previous C57BL/6J-specific SNP information was obtained by mapping the abundant reference sequence data of $\mathrm{C} 57 \mathrm{BL} / 6 \mathrm{~J}$ mice to the sequences of other strains. However, there was a lack of previous sequence data for $\mathrm{C} 57 \mathrm{BL} / 6 \mathrm{~N}$, and thus the detection of $\mathrm{C} 57 \mathrm{BL} / 6 \mathrm{~N}$ strainspecific SNPs was infeasible. Later, in 2011, a re-sequencing analysis of the C57BL/6NJ strain was performed [160,161], and highly accurate sequence information was published on the website of the Sanger Institute (Hinxton, United Kingdom; https://www.sanger. ac.uk/sanger/Mouse_SnpViewer/rel-1505). The results enabled a subsequent search for C57BL/6N strain SNPs and revealed SNP loci specific to the C57BL/6NJ strain and their genotypes in seventeen C57BL/6 substrains [7]. There were 86 polymorphic SNP loci at regular in- tervals on every chromosome, selected from approximately 1,400 C57BL6/NJ strain-specific SNP candidate loci. As results similar to those of the $\mathrm{C} 57 \mathrm{BL} / 6 \mathrm{~J}$ group, the number of C57BL/6N-specific SNPs was correlated with the branching year and breeding history of each lineage (see Fig. 1 in Mekada et al. 2015 [7]). The previous information required for genotyping each SNP locus listed in Mekada et al. 2015 [7] was updated with additional primer information for allele-specific PCR, and it is listed in Supplementary Table 3.

Our research group continues to search for SNPs that can distinguish among various $\mathrm{C} 57 \mathrm{BL} / 6$ substrains; such information is expected to improve our understanding of the genetic background of these strains. In addition to SNPs, DNA polymorphisms such as indels and short tandem repeats as well as structural variants, including C57BL/6-specific genetic variants found in Nnt and Snca genes, can be used to distinguish C57BL/6 strains in terms of genetic background $[14,115,162]$. These DNA polymorphism markers may be useful for comparing substrains and can also be applied to gene mapping involving the crossing of $\mathrm{C} 57 \mathrm{BL} / 6$ substrains. A genetic screening model based on these principles would enable the mapping of polymorphic loci that contribute to the variability of a trait among strains with a largely homogenous background; this could lead to improvements in mapping resolution and aid in the selection of candidate genes. To date, numerous quantitative trait loci have been identified, including genes associated with susceptibility to heat nociception [53], diet-induced obesity [84], dominant obesity [163], circadian activity [164], feeding disorder [37], response to cocaine [41], defective neutrophil recruitment [91], and non-ectopic endogenous retroviral dysregulation [92]. With advances in genome sequencing technology, genomic information for inbred mice, including substrains, is being continually updated $[165,166]$. It is expected that many new strain-specific haplotypes will be identified in the future.

Table 4. Genetic background of C57BL/6JBoy congenic strains

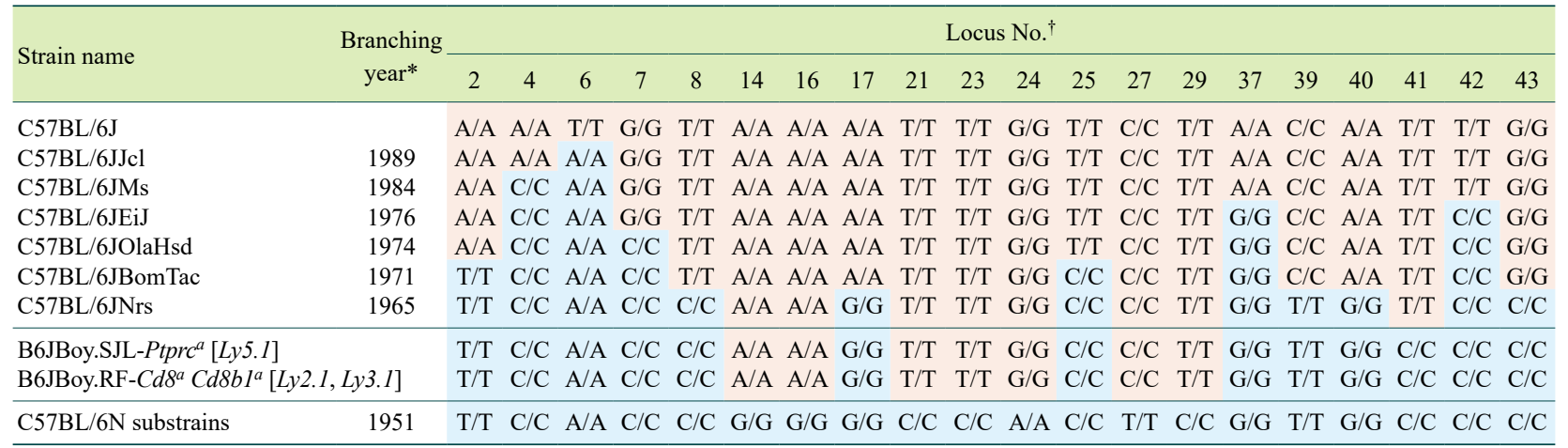

*The year in which each C57BL/6 substrain branched from the C57BL/6J strain of the Jackson Laboratory. ${ }^{\dagger}$ Corresponds to Locus No. in Supplementary Table 2. 


\section{Large-scale and Complex Resources}

C57BL/6J substrains have been the most widely used background for many mutant strains, including genetically-modified lines. Another major lineage, the C57BL/6N substrain, has been used as the genetic background for embryonic stem cells in large-scale generation of knockouts [12]. As a result, many mutant mice derived from the $\mathrm{C} 57 \mathrm{BL} / 6 \mathrm{~J}$ and $\mathrm{C} 57 \mathrm{BL} / 6 \mathrm{~N}$ substrains are used worldwide, including in Japan. However, given that the substrains are widely considered interchangeable, significant phenotypic differences among substrains are often overlooked. The phenotypic differences among C57BL/6 substrains reported to date should be considered by researchers. For example, certain substrains should be used with caution in conditional knockout models because conditional knockout mice should be crossed with Cre and/or Flp recombinase mice. Combining recombinase strains with different genetic backgrounds might produce knockout animals with mixed genetic backgrounds, leading to unexpected phenotypic variations. When the genetic backgrounds of experimental mice are not identical, erroneous conclusions are likely to be drawn. If a suitable substrain cannot be used, wild-type littermates might serve as an appropriate control group. Recently, it has become clear that phenotypic differences among substrains are caused by a complex combination of genetic and microbial alterations $[167,168]$. Use of wild-type littermates might standardize the microbiota, thereby facilitating investigation of the phenotype or function of specific genes that could be affected by the microbial community $[169,170]$.

\section{Genome-edited Mice}

Today, the rise in prominence of genome editing technologies has made it possible to directly generate various types of genetically modified mice, including gene knockout, conditional knockout, and gene knock-in, by using the fertilized eggs of inbred mice without the need for embryonic stem cells. At present, more than $50 \%$ of the strains deposited at the RIKEN BRC have been generated by genome editing using fertilized eggs from inbred strains, although not necessarily C57BL/6 mice. Just as there are $\mathrm{C} 57 \mathrm{BL} / 6$ substrains, there are also substrains of other inbred lines, and as is the case with the C57BL/6 strain, an accumulation of genetic and phenotypic differences is to be expected. More recently, many mouse models have been generated for coronavirus research; the BALB/c mouse strain is known to be popular in the immunology field and susceptible to SARS-CoV-2 $[171,172]$, and it is increasingly being used as a back- ground strain for COVID-19 research [173-175]. The $\mathrm{BALB} / \mathrm{c}$ strain has a long history in the form of the above B6 mice $[2,3]$. At least $16 \mathrm{BALB} / \mathrm{c}$ substrains, including $\mathrm{BALB} / \mathrm{cJ}, \mathrm{BALB} / \mathrm{cBy}$, and $\mathrm{BALB} / \mathrm{cAnN}$, available to the research community can be found by performing a PubMed research with the search term "BALB/c". Furthermore, several papers have reported phenotypic variations in infection and immune responses [176-178]. Therefore, we should pay much more attention to the substrain status of BALB/c mice in research on $\mathrm{COV}$ ID-19, which is increasing around the world.

\section{Conclusion}

Experimental data must be robust, reliable, and reproducible; only under these circumstances can science progress [179]. To ensure experimental reproducibility and minimize bias, researchers should recognize potential phenotypic differences among substrain mouse models, select appropriate substrains for their own research purposes, and share the full names of the substrains used with the scientific community. In the future, it is expected that journals will adopt a policy requiring a detailed description of the substrain and the breeding history of model mice used in research.

\section{Acknowledgments}

We are grateful to Masayo Kadota, Mayu Hirose, Ayumi Murakami, and the other members of the Experimental Animal Division, RIKEN BRC, for their devoted technical assistance. We also thank Ikuo Miura, Kuniya Abe, Toshihiko Shiroishi, Yuichi Obata, and Kazuo Moriwaki of RIKEN BRC for their valuable advice and support. This work was supported by a Grantin-Aid for Young Scientists (B) from the Ministry of Education, Culture, Sports, Science and Technology (MEXT) of Japan (Grant Number 23700518) to K.M. The RIKEN BioResource Research Center has been a participant in the National BioResource Project (NBRP) organized by MEXT and designated as the core facility for mouse resources of the NBRP.

\section{References}

1. Russell ES. Genetic origins and some research used of C57BL/6, DBA/2, and B6D2F1 mice. In: Gibson DC, Adelman RC, Finch C. editors. Development of the rodent as a model system of aging. Bethesda: DHEW Publ No. (NIH) 79-161; 1978. pp. 37-44.

2. Festing MF. Inbred strains in biomedical research. London and Basingstoke: The Macmillan Press; 1979.

3. Festing MF. Origins and characteristics of inbred strains of mice. In: Lyon MF, Rastan S, Brown SDM, editors. Genetic 
variants and strains of the laboratory mouse. Oxford: Oxford University Press; 1996 . pp. 1537-1576.

4. Altman PL, Kats DD. Inbred and genetically defined strains of laboratory animals, part 1 mouse and rat. Bethesda: Federation of American Societies for Experimental Biology; 1979.

5. Bailey DW. Sources of subline divergence and their relative importance for sublines of six major inbred strains of mice. In: Morse III HC. editor. Origins of inbred mice. New York: Academic Press; 1978. pp. 197-215.

6. Mekada K, Abe K, Murakami A, Nakamura S, Nakata H, Moriwaki K, et al. Genetic differences among C57BL/6 substrains. Exp Anim. 2009; 58: 141-149. [Medline] [CrossRef]

7. Mekada K, Hirose M, Murakami A, Yoshiki A. Development of SNP markers for C57BL/6N-derived mouse inbred strains. Exp Anim. 2015; 64: 91-100. [Medline] [CrossRef]

8. Waterston RH, Lindblad-Toh K, Birney E, Rogers J, Abril JF, Agarwal P, et al. Mouse Genome Sequencing Consortium. Initial sequencing and comparative analysis of the mouse genome. Nature. 2002; 420: 520-562. [Medline] [CrossRef]

9. Pettitt SJ, Liang Q, Rairdan XY, Moran JL, Prosser HM, Beier DR, et al. Agouti C57BL/6N embryonic stem cells for mouse genetic resources. Nat Methods. 2009; 6: 493-495. [Medline] [CrossRef]

10. Bradley A, Anastassiadis K, Ayadi A, Battey JF, Bell C, Birling MC, et al. The mammalian gene function resource: the International Knockout Mouse Consortium. Mamm Genome. 2012; 23: 580-586. [Medline] [CrossRef]

11. Brown SD, Moore MW. The International Mouse Phenotyping Consortium. The International Mouse Phenotyping Consortium: past and future perspectives on mouse phenotyping. Mamm Genome. 2012; 23: 632-640. [Medline] [CrossRef]

12. Collins FS, Rossant J, Wurst W. International Mouse Knockout Consortium. A mouse for reasons. Cell. 2007; 128: 9-13.

13. Meehan TF, Conte N, West DB, Jacobsen JO, Mason J, Warren $\mathrm{J}$, et al. International Mouse Phenotyping Consortium. Disease model discovery from 3,328 gene knockouts by The International Mouse Phenotyping Consortium. Nat Genet. 2017; 49: 1231-1238. [Medline] [CrossRef]

14. Dobrowolski P, Fischer M, Naumann R. Novel insights into the genetic background of genetically modified mice. Transgenic Res. 2018; 27: 265-275. [Medline] [CrossRef]

15. Åhlgren J, Voikar V. Experiments done in Black-6 mice: what does it mean? Lab Anim (NY). 2019; 48: 171-180. [Medline] [CrossRef]

16. Fontaine DA, Davis DB. Attention to background strain is essential for metabolic research: C57BL/6 and the International Knockout Mouse Consortium. Diabetes. 2016; 65: 25-33. [Medline] [CrossRef]

17. Sluyter F, Marican CC, Crusio WE. Further phenotypical characterisation of two substrains of C57BL/6J inbred mice differing by a spontaneous single-gene mutation. Behav Brain Res. 1999; 98: 39-43. [Medline] [CrossRef]

18. Blum K, Briggs AH, DeLallo L, Elston SF, Ochoa R. Whole brain methionine-enkephalin of ethanol-avoiding and ethanol-preferring C57BL mice. Experientia. 1982; 38: 1469 1470. [Medline] [CrossRef]

19. Khisti RT, Wolstenholme J, Shelton KL, Miles MF. Characterization of the ethanol-deprivation effect in substrains of C57BL/6 mice. Alcohol. 2006; 40: 119-126. [Medline] [CrossRef]

20. Poley W. Alcohol-preferring and alcohol-avoiding C57BL mice. Behav Genet. 1972; 2: 245-248. [Medline] [CrossRef]

21. Ramachandra V, Phuc S, Franco AC, Gonzales RA. Ethanol preference is inversely correlated with ethanol-induced dopamine release in 2 substrains of C57BL/6 mice. Alcohol Clin Exp Res. 2007; 31: 1669-1676. [Medline] [CrossRef]

22. Warden AS, DaCosta A, Mason S, Blednov YA, Mayfield $\mathrm{RD}$, Harris RA. Inbred substrain differences influence neuroimmune response and drinking behavior. Alcohol Clin Exp Res. 2020; 44: 1760-1768 [CrossRef]. [Medline]
23. Moisset B. Genetic analysis of the behavioral response to d-amphetamine in mice. Psychopharmacology (Berl). 1977; 53: 269-276. [Medline] [CrossRef]

24. Pinheiro BS, Seidl SS, Habazettl E, Gruber BE, Bregolin T, Zernig G. Dyadic social interaction of C57BL/6 mice versus interaction with a toy mouse: conditioned place preference/ aversion, substrain differences, and no development of a hierarchy. Behav Pharmacol. 2016; 27: 279-288. [Medline] [CrossRef]

25. Sturm M, Becker A, Schroeder A, Bilkei-Gorzo A, Zimmer A. Effect of chronic corticosterone application on depressionlike behavior in C57BL/6N and C57BL/6J mice. Genes Brain Behav. 2015; 14: 292-300. [Medline] [CrossRef]

26. Babbs RK, Beierle JA, Yao EJ, Kelliher JC, Medeiros AR, Anandakumar J, et al. The effect of the demyelinating agent cuprizone on binge-like eating of sweetened palatable food in female and male C57BL/6 substrains. Appetite. 2020; 150: 104678. [Medline] [CrossRef]

27. Kirkpatrick SL, Bryant CD. Behavioral architecture of opioid reward and aversion in C57BL/6 substrains. Front Behav Neurosci. 2015; 8: 450. [Medline] [CrossRef]

28. Matsuo N, Takao K, Nakanishi K, Yamasaki N, Tanda K, Miyakawa T. Behavioral profiles of three C57BL/6 substrains. Front Behav Neurosci. 2010; 4: 29. [Medline]

29. Labots M, Zheng X, Moattari G, Ohl F, van Lith HA. Effects of light regime and substrain on behavioral profiles of male C57BL/6 mice in three tests of unconditioned anxiety. J Neurogenet. 2016; 30: 306-315. [Medline] [CrossRef]

30. Hager T, Jansen RF, Pieneman AW, Manivannan SN, Golani I, van der Sluis S, et al. Display of individuality in avoidance behavior and risk assessment of inbred mice. Front Behav Neurosci. 2014; 8: 314. [Medline] [CrossRef]

31. Radulovic J, Kammermeier J, Spiess J. Generalization of fear responses in C57BL/6N mice subjected to one-trial foreground contextual fear conditioning. Behav Brain Res. 1998; 95: 179-189. [Medline] [CrossRef]

32. Siegmund A, Langnaese K, Wotjak CT. Differences in extinction of conditioned fear in $\mathrm{C} 57 \mathrm{BL} / 6$ substrains are unrelated to expression of alpha-synuclein. Behav Brain Res. 2005; 157: 291-298. [Medline] [CrossRef]

33. Siegmund A, Wotjak CT. A mouse model of posttraumatic stress disorder that distinguishes between conditioned and sensitised fear. J Psychiatr Res. 2007; 41: 848-860. [Medline] [CrossRef]

34. Stiedl O, Radulovic J, Lohmann R, Birkenfeld K, Palve M, Kammermeier J, et al. Strain and substrain differences in context- and tone-dependent fear conditioning of inbred mice. Behav Brain Res. 1999; 104: 1-12. [Medline] [CrossRef]

35. Bryant CD, Zhang NN, Sokoloff G, Fanselow MS, Ennes HS, Palmer AA, et al. Behavioral differences among C57BL/6 substrains: implications for transgenic and knockout studies. J Neurogenet. 2008; 22: 315-331. [Medline] [CrossRef]

36. Ashworth A, Bardgett ME, Fowler J, Garber H, Griffith M, Curran CP. Comparison of neurological function in males and females from two substrains of C57BL/6 Mice. Toxics. 2015; 3: 1-17. [Medline] [CrossRef]

37. Kirkpatrick SL, Goldberg LR, Yazdani N, Babbs RK, Wu J, Reed ER, et al. Cytoplasmic FMR1-interacting protein 2 is a major genetic factor underlying binge eating. Biol Psychiatry. 2017; 81: 757-769. [Medline] [CrossRef]

38. Cooper MA, O’Meara B, Jack MM, Elliot D, Lamb B, Khan $\mathrm{ZW}$, et al. Intrinsic activity of $\mathrm{C} 57 \mathrm{BL} / 6$ substrains associates with high-fat diet-induced mechanical sensitivity in mice. J Pain. 2018; 19: 1285-1295. [Medline] [CrossRef]

39. van Gaalen MM, Steckler T. Behavioural analysis of four mouse strains in an anxiety test battery. Behav Brain Res. 2000; 115: 95-106. [Medline] [CrossRef]

40. Shoji H, Miyakawa T. Increased depression-related behavior during the postpartum period in inbred BALB/c and C57BL/6 strains. Mol Brain. 2019; 12: 70. [Medline] [CrossRef] 
41. Kumar V, Kim K, Joseph C, Kourrich S, Yoo SH, Huang HC, et al. C57BL/6N mutation in cytoplasmic FMRP interacting protein 2 regulates cocaine response. Science. 2013; 342: 1508-1512. [Medline] [CrossRef]

42. Maroni MJ, Capri KM, Arruda NL, Gelineau RR, Deane HV, Concepcion HA, et al. Substrain specific behavioral responses in male C57BL/6N and C57BL/6J mice to a shortened 21-hour day and high-fat diet. Chronobiol Int. 2020; 37: 809-823. [Medline] [CrossRef]

43. Clapcote SJ, Roder JC. Survey of embryonic stem cell line source strains in the water maze reveals superior reversal learning of 129S6/SvEvTac mice. Behav Brain Res. 2004; 152: 35-48. [Medline]

44. Bothe GWM, Bolivar VJ, Vedder MJ, Geistfeld JG. Behavioral differences among fourteen inbred mouse strains commonly used as disease models. Comp Med. 2005; 55: 326 334. [Medline]

45. Kang M, Ryu HH, Lee YS. Comparisons of behavior and synaptic plasticity among three C57BL/6 substrains. Anim Cells Syst. 2015; 19: 181-187. [CrossRef]

46. Grottick AJ, Bagnol D, Phillips S, McDonald J, Behan DP, Chalmers DT, et al. Neurotransmission- and cellular stressrelated gene expression associated with prepulse inhibition in mice. Brain Res Mol Brain Res. 2005; 139: 153-162. [Medline] [CrossRef]

47. Ulker E, Caillaud M, Patel T, White A, Rashid D, Alqasem $\mathrm{M}$, et al. C57BL/6 substrain differences in formalin-induced pain-like behavioral responses. Behav Brain Res. 2020; 390: 112698. [Medline] [CrossRef]

48. Capri KM, Maroni MJ, Deane HV, Concepcion HA, DeCourcey H, Logan RW, et al. Male C57BL6/N and C57BL6/J mice respond differently to constant light and running-wheel access. Front Behav Neurosci. 2019; 13: 268. [Medline] [CrossRef]

49. Mirabelli E, Ni L, Li L, Acioglu C, Heary RF, Elkabes S. Pathological pain processing in mouse models of multiple sclerosis and spinal cord injury: contribution of plasma membrane calcium ATPase 2 (PMCA2). J Neuroinflammation. 2019; 16: 207. [Medline] [CrossRef]

50. Bankstahl M, Müller CJ, Wilk E, Schughart K, Löscher W. Generation and characterization of pilocarpine-sensitive C57BL/6 mice as a model of temporal lobe epilepsy. Behav Brain Res. 2012; 230: 182-191. [Medline] [CrossRef]

51. Müller CJ, Gröticke I, Hoffmann K, Schughart K, Löscher W. Differences in sensitivity to the convulsant pilocarpine in substrains and sublines of C57BL/6 mice. Genes Brain Behav. 2009; 8: 481-492. [Medline] [CrossRef]

52. Akinola LS, Mckiver B, Toma W, Zhu AZX, Tyndale RF, Kumar V, et al. C57BL/6 substrain differences in pharmacological effects after acute and repeated nicotine administration. Brain Sci. 2019; 9: 244. [Medline] [CrossRef]

53. Bryant CD, Bagdas D, Goldberg LR, Khalefa T, Reed ER, Kirkpatrick SL, et al. C57BL/6 substrain differences in inflammatory and neuropathic nociception and genetic mapping of a major quantitative trait locus underlying acute thermal nociception. Mol Pain. 2019; 15: 1744806918825046. [Medline] [CrossRef]

54. Henricks KK, Miner LL, Marley RJ. Differential cocaine sensitivity between two closely related substrains of C57BL mice. Psychopharmacology (Berl). 1997; 132: 161-168. [Medline] [CrossRef]

55. Otsuka S, Ohkido T, Itakura M, Watanabe S, Yamamori S, Iida Y, et al. Dual mechanisms of rapid expression of anxietyrelated behavior in pilocarpine-treated epileptic mice. Epilepsy Res. 2016; 123: 55-67. [Medline] [CrossRef]

56. Mayorga AJ, Lucki I. Limitations on the use of the C57BL/6 mouse in the tail suspension test. Psychopharmacology (Berl). 2001; 155: 110-112. [Medline] [CrossRef]

57. Roth DM, Swaney JS, Dalton ND, Gilpin EA, Ross J Jr. Impact of anesthesia on cardiac function during echocardiog- raphy in mice. Am J Physiol Heart Circ Physiol. 2002; 282: H2134-H2140. [Medline] [CrossRef]

58. Vaillant F, Lauzier B, Poirier I, Gélinas R, Rivard ME, Robillard Frayne I, et al. Mouse strain differences in metabolic fluxes and function of ex vivo working hearts. Am J Physiol Heart Circ Physiol. 2014; 306: H78-H87. [Medline] [CrossRef]

59. Moreth K, Fischer R, Fuchs H, Gailus-Durner V, Wurst W, Katus HA, et al. High-throughput phenotypic assessment of cardiac physiology in four commonly used inbred mouse strains. J Comp Physiol B. 2014; 184: 763-775. [Medline] [CrossRef]

60. Deckx S, Carai P, Bateman J, Heymans S, Papageorgiou AP. Breeding strategy determines rupture incidence in postinfarct healing WARPing cardiovascular research. PLoS One. 2015; 10: e0139199. [Medline] [CrossRef]

61. Williams JL, Paudyal A, Awad S, Nicholson J, Grzesik D, Botta J, et al. Mylk3 null C57BL/6N mice develop cardiomyopathy, whereas $N n t$ null C57BL/6J mice do not. Life Sci Alliance. 2020; 3: e201900593. [Medline] [CrossRef]

62. Vozenilek AE, Vetkoetter M, Green JM, Shen X, Traylor JG, Klein RL, et al. Absence of nicotinamide nucleotide transhydrogenase in C57BL/6J Mice exacerbates experimental atherosclerosis. J Vasc Res. 2018; 55: 98-110. [Medline] [CrossRef]

63. Cardin S, Scott-Boyer MP, Praktiknjo S, Jeidane S, Picard $\mathrm{S}$, Reudelhuber TL, et al. Differences in cell-type-specific responses to angiotensin II explain cardiac remodeling differences in C57BL/6 mouse substrains. Hypertension. 2014; 64: 1040-1046. [Medline] [CrossRef]

64. Garcia-Menendez L, Karamanlidis G, Kolwicz S, Tian R. Substrain specific response to cardiac pressure overload in C57BL/6 mice. Am J Physiol Heart Circ Physiol. 2013; 305: H397-H402. [Medline] [CrossRef]

65. Wolf S, Mattheis A, Laufs U, Meier C, Tschernig T. Mitochondrial regulation of reactive oxygen species (ROS) production-Unexpected observations in early postnatal cerebral vasculature. J Chem Neuroanat. 2016; 74: 1-4. [Medline] [CrossRef]

66. Zi M, Stafford N, Prehar S, Baudoin F, Oceandy D, Wang X, et al. Cardiac hypertrophy or failure? - A systematic evaluation of the transverse aortic constriction model in C57BL/6NTac and C57BL/6J substrains. Curr Res Physiol. 2019; 1: 1-10. [Medline] [CrossRef]

67. Combe R, Mudgett J, El Fertak L, Champy MF, AymeDietrich E, Petit-Demoulière B, et al. How does circadian rhythm impact salt sensitivity of blood pressure in mice? a study in two close C57B1/6 substrains. PLoS One. 2016; 11: e0153472. [Medline] [CrossRef]

68. Leskov I, Neville A, Shen X, Pardue S, Kevil CG, Granger $\mathrm{DN}$, et al. Nicotinamide nucleotide transhydrogenase activity impacts mitochondrial redox balance and the development of hypertension in mice. J Am Soc Hypertens. 2017; 11: 110 121. [Medline] [CrossRef]

69. Wolf S, Hainz N, Beckmann A, Maack C, Menger MD, Tschernig $\mathrm{T}$, et al. Brain damage resulting from postnatal hypoxic-ischemic brain injury is reduced in C57BL/6J mice as compared to C57BL/6N mice. Brain Res. 2016; 1650: 224-231. [Medline] [CrossRef]

70. MacBride MM, Navis A, Dasari A, Perez AV. Mild reproductive impact of a Y chromosome deletion on a C57BL/6J substrain. Mamm Genome. 2017; 28: 155-165. [Medline] [CrossRef]

71. Oldford C, Kuksal N, Gill R, Young A, Mailloux RJ. Estimation of the hydrogen peroxide producing capacities of liver and cardiac mitochondria isolated from $\mathrm{C} 57 \mathrm{BL} / 6 \mathrm{~N}$ and C57BL/6J mice. Free Radic Biol Med. 2019; 135: 15-27. [Medline] [CrossRef]

72. Ronchi JA, Figueira TR, Ravagnani FG, Oliveira HC, Vercesi AE, Castilho RF. A spontaneous mutation in the nicotinamide 
nucleotide transhydrogenase gene of $\mathrm{C} 57 \mathrm{BL} / 6 \mathrm{~J}$ mice results in mitochondrial redox abnormalities. Free Radic Biol Med. 2013; 63: 446-456. [Medline] [CrossRef]

73. Green ML, Singh AV, Zhang Y, Nemeth KA, Sulik KK, Knudsen TB. Reprogramming of genetic networks during initiation of the Fetal Alcohol Syndrome. Dev Dyn. 2007; 236: 613-631. [Medline] [CrossRef]

74. Anthony B, Vinci-Booher S, Wetherill L, Ward R, Goodlett C, Zhou FC. Alcohol-induced facial dysmorphology in C57BL/6 mouse models of fetal alcohol spectrum disorder. Alcohol. 2010; 44: 659-671. [Medline] [CrossRef]

75. Fischer LA, Bittner-Eddy PD, Costalonga M. Fetal weight outcomes in $\mathrm{C} 57 \mathrm{BL} / 6 \mathrm{~J}$ and $\mathrm{C} 57 \mathrm{BL} / 6 \mathrm{NCrl}$ mice after oral colonization with Porphyromonas gingivalis. Infect Immun. 2019; 87: e00280-e19. [Medline] [CrossRef]

76. Ulmasov B, Oshima K, Rodriguez MG, Cox RD, Neuschwander-Tetri BA. Differences in the degree of cerulein-induced chronic pancreatitis in C57BL/6 mouse substrains lead to new insights in identification of potential risk factors in the development of chronic pancreatitis. Am J Pathol. 2013; 183: 692-708. [Medline] [CrossRef]

77. Kendall A, Schacht J. Disparities in auditory physiology and pathology between $\mathrm{C} 57 \mathrm{BL} / 6 \mathrm{~J}$ and $\mathrm{C} 57 \mathrm{BL} / 6 \mathrm{~N}$ substrains. Hear Res. 2014; 318: 18-22. [Medline] [CrossRef]

78. Morales-Hernández A, Martinat A, Chabot A, Kang G, McKinney-Freeman S. Elevated oxidative stress impairs hematopoietic progenitor function in C57BL/6 substrains. Stem Cell Reports. 2018; 11: 334-347. [Medline] [CrossRef]

79. Otto GP, Rathkolb B, Oestereicher MA, Lengger CJ, Moerth $\mathrm{C}$, Micklich $\mathrm{K}$, et al. Clinical chemistry reference intervals for $\mathrm{C} 57 \mathrm{BL} / 6 \mathrm{~J}, \mathrm{C} 57 \mathrm{BL} / 6 \mathrm{~N}$, and $\mathrm{C} 3 \mathrm{HeB} / \mathrm{FeJ}$ Mice (Mus musculus). J Am Assoc Lab Anim Sci. 2016; 55: 375-386. [Medline]

80. Andersson KE, Immerstrand T, Swärd K, Bergenståhl B, Lindholm MW, Oste R, et al. Effects of oats on plasma cholesterol and lipoproteins in C57BL/6 mice are substrain specific. Br J Nutr. 2010; 103: 513-521. [Medline] [CrossRef]

81. Marques O, Neves J, Horvat NK, Colucci S, Guida C, Muckenthaler MU. Iron-related parameters are altered between C57BL/6N and C57BL/6J Mus musculus wild-type substrains. HemaSphere. 2019; 3: e304. [Medline] [CrossRef]

82. Hull RL, Willard JR, Struck MD, Barrow BM, Brar GS, Andrikopoulos $\mathrm{S}$, et al. High fat feeding unmasks variable insulin responses in male C57BL/6 mouse substrains. J Endocrinol. 2017; 233: 53-64. [Medline] [CrossRef]

83. Ge MQ, Yeung SC, Mak JCW, Ip MSM. Differential metabolic and inflammatory responses to intermittent hypoxia in substrains of lean and obese C57BL/6 mice. Life Sci. 2019; 238: 116959. [Medline] [CrossRef]

84. Heiker JT, Kunath A, Kosacka J, Flehmig G, Knigge A, Kern $\mathrm{M}$, et al. Identification of genetic loci associated with different responses to high-fat diet-induced obesity in C57BL/6N and C57BL/6J substrains. Physiol Genomics. 2014; 46: 377 384. [Medline] [CrossRef]

85. Kern M, Knigge A, Heiker JT, Kosacka J, Stumvoll M, Kovacs $\mathrm{P}$, et al. C57BL/6JRj mice are protected against diet induced obesity (DIO). Biochem Biophys Res Commun. 2012; 417: 717-720. [Medline] [CrossRef]

86. Nicholson A, Reifsnyder PC, Malcolm RD, Lucas CA, MacGregor GR, Zhang W, et al. Diet-induced obesity in two C57BL/6 substrains with intact or mutant nicotinamide nucleotide transhydrogenase (Nnt) gene. Obesity (Silver Spring). 2010; 18: 1902-1905. [Medline] [CrossRef]

87. Fergusson G, Ethier M, Guévremont M, Chrétien C, Attané $\mathrm{C}$, Joly E, et al. Defective insulin secretory response to intravenous glucose in $\mathrm{C} 57 \mathrm{Bl} / 6 \mathrm{~J}$ compared to $\mathrm{C} 57 \mathrm{Bl} / 6 \mathrm{~N}$ mice. Mol Metab. 2014; 3: 848-854. [Medline] [CrossRef]

88. Fisher-Wellman KH, Ryan TE, Smith CD, Gilliam LA, Lin $\mathrm{CT}$, Reese LR, et al. A direct comparison of metabolic responses to high-fat diet in C57BL/6J and C57BL/6NJ mice.
Diabetes. 2016; 65: 3249-3261. [Medline] [CrossRef]

89. Siersbæk MS, Ditzel N, Hejbøl EK, Præstholm SM, Markussen LK, Avolio F, et al. C57BL/6J substrain differences in response to high-fat diet intervention. Sci Rep. 2020; 10: 14052. [Medline] [CrossRef]

90. Rendina-Ruedy E, Hembree KD, Sasaki A, Davis MR, Lightfoot SA, Clarke SL, et al. A Comparative Study of the Metabolic and Skeletal Response of C57BL/6J and C57BL/6N Mice in a Diet-Induced Model of Type 2 Diabetes. J Nutr Metab. 2015; 2015: 758080. [Medline] [CrossRef]

91. Ulland TK, Jain N, Hornick EE, Elliott EI, Clay GM, Sadler $\mathrm{JJ}$, et al. Nlrp12 mutation causes C57BL/6J strain-specific defect in neutrophil recruitment. Nat Commun. 2016; 7: 13180. [Medline] [CrossRef]

92. Treger RS, Pope SD, Kong Y, Tokuyama M, Taura M, Iwasaki A. The lupus susceptibility locus $S g p 3$ encodes the suppressor of endogenous retrovirus expression SNERV. Immunity. 2019; 50: 334-347.e9. [Medline] [CrossRef]

93. Eisfeld AJ, Gasper DJ, Suresh M, Kawaoka Y. C57BL/6J and C57BL/6NJ mice are differentially susceptible to inflammation-associated disease caused by influenza A virus. Front Microbiol. 2019; 9: 3307. [Medline] [CrossRef]

94. Garifulin O, Qi Z, Shen H, Patnala S, Green MR, Boyartchuk V. Irf3 polymorphism alters induction of interferon beta in response to Listeria monocytogenes infection. PLoS Genet. 2007; 3: 1587-1597. [Medline] [CrossRef]

95. Bezdek S, Hdnah A, Sezin T, Mousavi S, Zillikens D, Ibrahim S, et al. The genetic difference between $\mathrm{C} 57 \mathrm{Bl} / 6 \mathrm{~J}$ and C57Bl/6N mice significantly impacts Aldara $^{\mathrm{TM}_{\text {-induced }}}$ psoriasiform dermatitis. Exp Dermatol. 2017; 26: 349-351. [Medline] [CrossRef]

96. Duan L, Davis JS, Woolbright BL, Du K, Cahkraborty M, Weemhoff J, et al. Differential susceptibility to acetaminophen-induced liver injury in sub-strains of C57BL/6 mice: 6N versus 6J. Food Chem Toxicol. 2016; 98:(Pt B): 107-118. [Medline] [CrossRef]

97. Kawashita E, Ishihara K, Nomoto M, Taniguchi M, Akiba S. A comparative analysis of hepatic pathological phenotypes in $\mathrm{C} 57 \mathrm{BL} / 6 \mathrm{~J}$ and $\mathrm{C} 57 \mathrm{BL} / 6 \mathrm{~N}$ mouse strains in non-alcoholic steatohepatitis models. Sci Rep. 2019; 9: 204. [Medline] [CrossRef]

98. Diwan BA, Blackman KE. Differential susceptibility of 3 sublines of C57BL/6 mice to the induction of colorectal tumors by 1,2-dimethylhydrazine. Cancer Lett. 1980; 9: 111115. [Medline] [CrossRef]

99. Kalish S, Lyamina S, Chausova S, Kochetova L, Malyshev $\mathrm{Y}$, Manukhina E, et al. C57BL/6N mice are more resistant to Ehrlich ascites tumors than C57BL/6J mice: the tole of macrophage nitric oxide. Med Sci Monit Basic Res. 2015; 21: 235-240. [Medline] [CrossRef]

100. Zhao L, Mulligan MK, Nowak TS Jr. Substrain- and sex-dependent differences in stroke vulnerability in C57BL/6 mice. J Cereb Blood Flow Metab. 2019; 39: 426-438. [Medline] [CrossRef]

101. Tonelli Gombalová Z, Košuth J, Alexovič Matiašová A, Zrubáková J, Žežula I, Giallongo T, et al. Majority of cerebrospinal fluid-contacting neurons in the spinal cord of $\mathrm{C} 57 \mathrm{~B} 1 / 6 \mathrm{~N}$ mice is present in ectopic position unlike in other studied experimental mice strains and mammalian species. J Comp Neurol. 2020; 528: 2523-2550. [Medline] [CrossRef]

102. Crusio WE, Schwegler H, van Abeelen JH. Behavioural and neuroanatomical divergence between two sublines of C57BL/6J inbred mice. Behav Brain Res. 1991; 42: 93-97. [Medline] [CrossRef]

103. Jamot L, Bertholet JY, Crusio WE. Neuroanatomical divergence between two substrains of C57BL/6J inbred mice entails differential radial-maze learning. Brain Res. 1994; 644: 352-356. [Medline] [CrossRef]

104. Mangaru Z, Salem E, Sherman M, Van Dine SE, Bhambri A, Brumberg JC, et al. Neuronal migration defect of the devel- 
oping cerebellar vermis in substrains of C57BL/6 mice: cytoarchitecture and prevalence of molecular layer heterotopia. Dev Neurosci. 2013; 35: 28-39. [Medline] [CrossRef]

105. Karthivashan G, Park SY, Kim JS, Cho DY, Ganesan P, Choi DK. Comparative studies on behavioral, cognitive and biomolecular profiling of ICR, C57BL/6 and its sub-strains suitable for scopolamine-induced amnesic models. Int J Mol Sci. 2017; 18: 1735. [Medline] [CrossRef]

106. Usami M, Okada A, Taguchi K, Hamamoto S, Kohri K, Yasui T. Genetic differences in C57BL/6 mouse substrains affect kidney crystal deposition. Urolithiasis. 2018; 46: 515-522. [Medline] [CrossRef]

107. Chang HY, Mitzner W, Watson J. Variation in airway responsiveness of male C57BL/6 mice from 5 vendors. J Am Assoc Lab Anim Sci. 2012; 51: 401-406. [Medline]

108. Will JP, Hirani D, Thielen F, Klein F, Vohlen C, Dinger K, et al. Strain-dependent effects on lung structure, matrix remodeling, and Stat $3 / \mathrm{Smad} 2$ signaling in $\mathrm{C} 57 \mathrm{BL} / 6 \mathrm{~N}$ and C57BL/6J mice after neonatal hyperoxia. Am J Physiol Regul Integr Comp Physiol. 2019; 317: R169-R181. [Medline] [CrossRef]

109. Sankaran JS, Varshney M, Judex S. Differences in bone structure and unloading-induced bone loss between $\mathrm{C} 57 \mathrm{BL} / 6 \mathrm{~N}$ and C57BL/6J mice. Mamm Genome. 2017; 28: 476-486. [Medline] [CrossRef]

110. Liron T, Raphael B, Hiram-Bab S, Bab IA, Gabet Y. Bone loss in $\mathrm{C} 57 \mathrm{BL} / 6 \mathrm{~J}-\mathrm{OlaHsd}$ mice, a substrain of $\mathrm{C} 57 \mathrm{BL} / 6 \mathrm{~J}$ carrying mutated alpha-synuclein and multimerin-1 genes. J Cell Physiol. 2018; 233: 371-377. [Medline] [CrossRef]

111. Banks G, Heise I, Starbuck B, Osborne T, Wisby L, Potter $\mathrm{P}$, et al. Genetic background influences age-related decline in visual and nonvisual retinal responses, circadian rhythms, and sleep. Neurobiol Aging. 2015; 36: 380-393. [Medline] [CrossRef]

112. Ranson A, Cheetham CE, Fox K, Sengpiel F. Homeostatic plasticity mechanisms are required for juvenile, but not adult, ocular dominance plasticity. Proc Natl Acad Sci USA. 2012; 109: 1311-1316. [Medline] [CrossRef]

113. Schnabolk G, Stauffer K, O'Quinn E, Coughlin B, Kunchithapautham K, Rohrer B. A comparative analysis of C57BL/6 J and $6 \mathrm{~N}$ substrains; chemokine/cytokine expression and susceptibility to laser-induced choroidal neovascularization. Exp Eye Res. 2014; 129: 18-23. [Medline] [CrossRef]

114. Lajko M, Cardona HJ, Taylor JM, Farrow KN, Fawzi AA. Photoreceptor oxidative stress in hyperoxia-induced proliferative retinopathy accelerates $r d 8$ degeneration. PLoS One. 2017; 12: e0180384. [Medline] [CrossRef]

115. Simon MM, Greenaway S, White JK, Fuchs H, Gailus-Durner V, Wells S, et al. A comparative phenotypic and genomic analysis of C57BL/6J and C57BL/6N mouse strains. Genome Biol. 2013; 14: R82. [Medline] [CrossRef]

116. Smith CL, Goldsmith CA, Eppig JT. The Mammalian Phenotype Ontology as a tool for annotating, analyzing and comparing phenotypic information. Genome Biol. 2005; 6: R7. [Medline] [CrossRef]

117. Huang TT, Naeemuddin M, Elchuri S, Yamaguchi M, Kozy HM, Carlson EJ, et al. Genetic modifiers of the phenotype of mice deficient in mitochondrial superoxide dismutase. Hum Mol Genet. 2006; 15: 1187-1194. [Medline] [CrossRef]

118. Toye AA, Lippiat JD, Proks P, Shimomura K, Bentley L, Hugill $\mathrm{A}$, et al. A genetic and physiological study of impaired glucose homeostasis control in C57BL/6J mice. Diabetologia. 2005; 48: 675-686. [Medline] [CrossRef]

119. Specht CG, Schoepfer R. Deletion of the alpha-synuclein locus in a subpopulation of $\mathrm{C} 57 \mathrm{BL} / 6 \mathrm{~J}$ inbred mice. BMC Neurosci. 2001; 2: 11. [Medline] [CrossRef]

120. Specht CG, Schoepfer R. Deletion of multimerin-1 in alphasynuclein-deficient mice. Genomics. 2004; 83: 1176-1178. [Medline] [CrossRef]

121. Mattapallil MJ, Wawrousek EF, Chan CC, Zhao H, Roy- choudhury J, Ferguson TA, et al. The $R d 8$ mutation of the $\mathrm{Crb1}$ gene is present in vendor lines of $\mathrm{C} 57 \mathrm{BL} / 6 \mathrm{~N}$ mice and embryonic stem cells, and confounds ocular induced mutant phenotypes. Invest Ophthalmol Vis Sci. 2012; 53: 29212927. [Medline] [CrossRef]

122. Mehalow AK, Kameya S, Smith RS, Hawes NL, Denegre JM, Young JA, et al. CRB1 is essential for external limiting membrane integrity and photoreceptor morphogenesis in the mammalian retina. Hum Mol Genet. 2003; 12: 2179-2189. [Medline] [CrossRef]

123. Mahajan VS, Demissie E, Mattoo H, Viswanadham V, Varki A, Morris R, et al. Striking immune phenotypes in diverse gene-targeted mice are driven by a copy number variant originating from a commercially available C57BL/6 strain. Cell Rep. 2016; 15: 1901-1909. [Medline] [CrossRef]

124. Purtha WE, Swiecki M, Colonna M, Diamond MS, Bhattacharya D. Spontaneous mutation of the Dock2 gene in $\operatorname{Irf5} 5^{-1-}$ mice complicates interpretation of type I interferon production and antibody responses. Proc Natl Acad Sci USA. 2012; 109: E898-E904. [Medline] [CrossRef]

125. Fischer M, Kosyakova N, Liehr T, Dobrowolski P. Large deletion on the Y-chromosome long arm (Yq) of C57BL/6JBomTac inbred mice. Mamm Genome. 2017; 28: 31-37. [Medline] [CrossRef]

126. Freeman HC, Hugill A, Dear NT, Ashcroft FM, Cox RD. Deletion of nicotinamide nucleotide transhydrogenase: a new quantitive trait locus accounting for glucose intolerance in C57BL/6J mice. Diabetes. 2006; 55: 2153-2156. [Medline] [CrossRef]

127. Bourdi M, Davies JS, Pohl LR. Mispairing C57BL/6 substrains of genetically engineered mice and wild-type controls can lead to confounding results as it did in studies of JNK2 in acetaminophen and concanavalin A liver injury. Chem Res Toxicol. 2011; 24: 794-796. [Medline] [CrossRef]

128. Rao KNS, Shen X, Pardue S, Krzywanski DM. Nicotinamide nucleotide transhydrogenase (NNT) regulates mitochondrial ROS and endothelial dysfunction in response to angiotensin II. Redox Biol. 2020; 36: 101650. [Medline] [CrossRef]

129. Spillantini MG, Schmidt ML, Lee VM, Trojanowski JQ, Jakes R, Goedert M. Alpha-synuclein in Lewy bodies. Nature. 1997; 388: 839-840. [Medline] [CrossRef]

130. Asuni AA, Hilton K, Siskova Z, Lunnon K, Reynolds $\mathrm{R}$, Perry $\mathrm{VH}$, et al. Alpha-synuclein deficiency in the C57BL/6JOlaHsd strain does not modify disease progression in the ME7-model of prion disease. Neuroscience. 2010; 165: 662-674. [Medline] [CrossRef]

131. Pelkonen A, Yavich L. Neuromuscular pathology in mice lacking alpha-synuclein. Neurosci Lett. 2011; 487: 350-353. [Medline] [CrossRef]

132. Peña-Oliver Y, Buchman VL, Dalley JW, Robbins TW, Schumann G, Ripley TL, et al. Deletion of alpha-synuclein decreases impulsivity in mice. Genes Brain Behav. 2012; 11: 137-146. [Medline] [CrossRef]

133. Peña-Oliver Y, Sanchez-Roige S, Stephens DN, Ripley TL. Alpha-synuclein deletion decreases motor impulsivity but does not affect risky decision making in a mouse Gambling Task. Psychopharmacology (Berl). 2014; 231: 2493-2506. [Medline] [CrossRef]

134. Wong SY, Coffre M, Ramanan D, Hines MJ, Gomez LE, Peters LA, et al. B cell defects observed in Nod 2 knockout mice are a consequence of a Dock 2 mutation frequently found in inbred strains. J Immunol. 2018; 201: 1442-1451. [Medline] [CrossRef]

135. Kang SK, Hawkins NA, Kearney JA. C57BL/6J and C57BL/6N substrains differentially influence phenotype severity in the $\mathrm{Scnla}{ }^{+/-}$mouse model of Dravet syndrome. Epilepsia Open. 2018; 4: 164-169. [Medline] [CrossRef]

136. Kopić A, Benamara K, Schuster M, Leidenmühler P, Bauer A, Glantschnig $\mathrm{H}$, et al. Coagulation phenotype of wild-type mice on different genetic backgrounds. Lab Anim. 2019; 53: 
43-52. [Medline] [CrossRef]

137. Newberry EP, Kennedy S, Xie Y, Luo J, Jiang H, Ory DS, et al. Phenotypic divergence in two lines of $L-F a b p^{-/-}$mice reflects substrain differences and environmental modifiers. Am J Physiol Gastrointest Liver Physiol. 2015; 309: G648-G661. [Medline] [CrossRef]

138. Öztürk S, Roessner PM, Schulze-Edinghausen L, Yazdanparast H, Kalter V, Lichter P, et al. Rejection of adoptively transferred $\mathrm{E} \mu$-TCL1 chronic lymphocytic leukemia cells in C57BL/6 substrains or knockout mouse lines. Leukemia. 2019; 33: 1514-1539. [Medline] [CrossRef]

139. Eicher EM, Shown EP, Washburn LL. Sex reversal in C57BL/6J-YPOS mice corrected by a Sry transgene. Philos Trans R Soc Lond B Biol Sci. 1995; 350: 263-268, discussion 268-269. [Medline] [CrossRef]

140. Eicher EM, Washburn LL, Whitney JB 3rd, Morrow KE. Mus poschiavinus $\mathrm{Y}$ chromosome in the C57BL/6J murine genome causes sex reversal. Science. 1982; 217: 535-537. [Medline] [CrossRef]

141. Umemura Y, Miyamoto R, Hashimoto R, Kinoshita K, Omotehara T, Nagahara D, et al. Ontogenic and morphological study of gonadal formation in genetically-modified sex reversal XY(POS) mice. J Vet Med Sci. 2016; 77: 1587 1598. [Medline] [CrossRef]

142. Yokoyama T, Miura Y, Yamamoto A, Hasegawa C, Kawanishi K, Takada N, et al. Genetic differences between C57BL/6 substrains affect the process of testis differentiation in $\mathrm{Y}^{\mathrm{POS}}$ mice. J Vet Med Sci. 2019; 81: 608-611. [Medline] [CrossRef]

143. Nowak TS Jr, Mulligan MK. Impact of C57BL/6 substrain on sex-dependent differences in mouse stroke models. Neurochem Int. 2019; 127: 12-21. [Medline] [CrossRef]

144. Grupe A, Germer S, Usuka J, Aud D, Belknap JK, Klein RF, et al. In silico mapping of complex disease-related traits in mice. Science. 2001; 292: 1915-1918. [Medline] [CrossRef]

145. Petkov PM, Ding Y, Cassell MA, Zhang W, Wagner G, Sargent EE, et al. An efficient SNP system for mouse genome scanning and elucidating strain relationships. Genome Res. 2004; 14: 1806-1811. [Medline] [CrossRef]

146. Tsang S, Sun Z, Luke B, Stewart C, Lum N, Gregory M, et al. A comprehensive SNP-based genetic analysis of inbred mouse strains. Mamm Genome. 2005; 16: 476-480. [Medline] [CrossRef]

147. Wade CM, Kulbokas EJ 3rd, Kirby AW, Zody MC, Mullikin JC, Lander ES, et al. The mosaic structure of variation in the laboratory mouse genome. Nature. 2002; 420: 574-578. [Medline] [CrossRef]

148. Wiltshire T, Pletcher MT, Batalov S, Barnes SW, Tarantino LM, Cooke MP, et al. Genome-wide single-nucleotide polymorphism analysis defines haplotype patterns in mouse. Proc Natl Acad Sci USA. 2003; 100: 3380-3385. [Medline] [CrossRef]

149. Zhang J, Hunter KW, Gandolph M, Rowe WL, Finney RP, Kelley JM, et al. A high-resolution multistrain haplotype analysis of laboratory mouse genome reveals three distinctive genetic variation patterns. Genome Res. 2005; 15: 241-249. [Medline] [CrossRef]

150. Petkov PM, Cassell MA, Sargent EE, Donnelly CJ, Robinson $\mathrm{P}, \mathrm{Crew} \mathrm{V}$, et al. Development of a SNP genotyping panel for genetic monitoring of the laboratory mouse. Genomics. 2004; 83: 902-911. [Medline] [CrossRef]

151. Wakana S, Suzuki T, Furuse T, Kobayashi K, Miura I, Kane$\mathrm{da} \mathrm{H}$, et al. Introduction to the Japan Mouse Clinic at the RIKEN BioResource Center. Exp Anim. 2009; 58: 443-450. [Medline] [CrossRef]

152. Zurita E, Chagoyen M, Cantero M, Alonso R, González-Neira A, López-Jiménez A, et al. Genetic polymorphisms among C57BL/6 mouse inbred strains. Transgenic Res. 2011; 20: 481-489. [Medline] [CrossRef]

153. Levine AG, Mendoza A, Hemmers S, Moltedo B, Niec RE,
Schizas M, et al. Stability and function of regulatory T cells expressing the transcription factor T-bet. Nature. 2017; 546: 421-425. [Medline] [CrossRef]

154. Mise-Omata S, Alles N, Fukazawa T, Aoki K, Ohya K, Jimi E, et al. NF- $\mathrm{kB}$ RELA-deficient bone marrow macrophages fail to support bone formation and to maintain the hematopoietic niche after lethal irradiation and stem cell transplantation. Int Immunol. 2014; 26: 607-618. [Medline] [CrossRef]

155. Shen FW, Saga Y, Litman G, Freeman G, Tung JS, Cantor H, et al. Cloning of Ly-5 cDNA. Proc Natl Acad Sci USA. 1985; 82: 7360-7363. [Medline] [CrossRef]

156. Tung JS, Scheid MP, Pierotti MA, Hämmerling U, Boyse EA. Structural features and selective expression of three Ly-5+ cell-surface molecules. Immunogenetics. 1981; 14: 101-106. [Medline] [CrossRef]

157. Klein J. List of congenic lines of mice. I. Lines with differences at alloantigen loci. Transplantation. 1973; 15: 137-153. [Medline] [CrossRef]

158. Chisolm DA, Cheng W, Colburn SA, Silva-Sanchez A, MezaPerez S, Randall TD, et al. Defining genetic variation in widely used congenic and backcrossed mouse models reveals varied regulation of genes important for immune responses. Immunity. 2019; 51: 155-168.e5. [Medline] [CrossRef]

159. Jang Y, Gerbec ZJ, Won T, Choi B, Podsiad A, B Moore B, et al. Cutting edge: check your mice-a point mutation in the Ncrl locus identified in CD45.1 congenic mice with consequences in mouse susceptibility to infection. J Immunol. 2018; 200: 1982-1987. [Medline] [CrossRef]

160. Keane TM, Goodstadt L, Danecek P, White MA, Wong K, Yalcin B, et al. Mouse genomic variation and its effect on phenotypes and gene regulation. Nature. 2011; 477: 289-294. [Medline] [CrossRef]

161. Yalcin B, Wong K, Agam A, Goodson M, Keane TM, Gan X, et al. Sequence-based characterization of structural variation in the mouse genome. Nature. 2011; 477: 326-329. [Medline] [CrossRef]

162. Egan CM, Sridhar S, Wigler M, Hall IM. Recurrent DNA copy number variation in the laboratory mouse. Nat Genet. 2007; 39: 1384-1389. [Medline] [CrossRef]

163. Hossain MS, Asano F, Fujiyama T, Miyoshi C, Sato M, Ikkyu A, et al. Identification of mutations through dominant screening for obesity using C57BL/6 substrains. Sci Rep. 2016; 6: 32453. [Medline] [CrossRef]

164. Corty RW, Kumar V, Tarantino LM, Takahashi JS, Valdar W. Mean-variance QTL mapping identifies novel QTL for circadian activity and exploratory behavior in mice. G3 (Bethesda). 2018; 8: 3783-3790. [Medline]

165. Lilue J, Doran AG, Fiddes IT, Abrudan M, Armstrong J, Bennett R, et al. Sixteen diverse laboratory mouse reference genomes define strain-specific haplotypes and novel functional loci. Nat Genet. 2018; 50: 1574-1583. [Medline] [CrossRef]

166. Sarsani VK, Raghupathy N, Fiddes IT, Armstrong J, ThibaudNissen F, Zinder O, et al. The genome of C57BL/6J "Eve", the mother of the laboratory mouse genome reference strain. G3 (Bethesda). 2019; 9: 1795-1805. [Medline]

167. Huang E, Kang S, Park H, Park S, Ji Y, Holzapfel WH. Differences in anxiety levels of various murine models in relation to the gut microbiota composition. Biomedicines. 2018; 6: 113. [Medline] [CrossRef]

168. Smoczek M, Vital M, Wedekind D, Basic M, Zschemisch $\mathrm{NH}$, Pieper DH, et al. A combination of genetics and microbiota influences the severity of the obesity phenotype in dietinduced obesity. Sci Rep. 2020; 10: 6118. [Medline] [CrossRef]

169. Stappenbeck TS, Virgin HW. Accounting for reciprocal hostmicrobiome interactions in experimental science. Nature. 2016; 534: 191-199. [Medline] [CrossRef]

170. Ubeda C, Lipuma L, Gobourne A, Viale A, Leiner I, Equinda $\mathrm{M}$, et al. Familial transmission rather than defective innate immunity shapes the distinct intestinal microbiota of TLR- 
deficient mice. J Exp Med. 2012; 209: 1445-1456. [Medline] [CrossRef]

171. Roberts A, Paddock C, Vogel L, Butler E, Zaki S, Subbarao $\mathrm{K}$. Aged BALB/c mice as a model for increased severity of severe acute respiratory syndrome in elderly humans. J Virol. 2005; 79: 5833-5838. [Medline] [CrossRef]

172. Wentworth DE, Gillim-Ross L, Espina N, Bernard KA. Mice susceptible to SARS coronavirus. Emerg Infect Dis. 2004; 10: 1293-1296. [Medline] [CrossRef]

173. Dinnon KH 3rd, Leist SR, Schäfer A, Edwards CE, Martinez DR, Montgomery SA, et al. A mouse-adapted model of SARS-CoV-2 to test COVID-19 countermeasures. Nature. 2020; 586: 560-566. [Medline] [CrossRef]

174. Hassan AO, Case JB, Winkler ES, Thackray LB, Kafai NM, Bailey AL, et al. A SARS-CoV-2 infection model in mice demonstrates protection by neutralizing antibodies. Cell. 2020; 182: 744-753.e4. [Medline] [CrossRef]

175. Weston S, Coleman CM, Haupt R, Logue J, Matthews K, Li $\mathrm{Y}$, et al. Broad anti-coronaviral activity of Food and Drug Administration approved drugs against SARS-CoV-2 in vitro and SARS-CoV in vivo. J Virol. 2020; e01218-20. [Medline] [CrossRef]

176. Kaushansky A, Austin LS, Mikolajczak SA, Lo FY, Miller JL, Douglass AN, et al. Susceptibility to Plasmodium yoelii preerythrocytic infection in BALB/c substrains is determined at the point of hepatocyte invasion. Infect Immun. 2015; 83: 39-47. [Medline] [CrossRef]

177. Nicholson SM, Peterson JD, Miller SD, Wang K, Dal Canto MC, Melvold RW. BALB/c substrain differences in susceptibility to Theiler's murine encephalomyelitis virus-induced demyelinating disease. J Neuroimmunol. 1994; 52: 19-24. [Medline] [CrossRef]

178. Poyntz HC, Jones A, Jauregui R, Young W, Gestin A, Mooney $A$, et al. Genetic regulation of antibody responsiveness to immunization in substrains of BALB/c mice. Immunol Cell Biol. 2019; 97: 39-53. [Medline] [CrossRef]

179. Percie du Sert N, Hurst V, Ahluwalia A, Alam S, Avey MT, Baker M, et al. The ARRIVE guidelines 2.0: Updated guidelines for reporting animal research. PLoS Biol. 2020; 18: e3000410. [Medline] [CrossRef] 